\title{
Laser shock peening (LSP): Electrochemical and hydrodynamic investigation of corrosion protection pre-treatment for a copper surface in $3.5 \% \mathrm{NaCl}$ medium
}

\author{
V.I. Chukwuike ${ }^{\mathrm{a}, \mathrm{b}}$, O.G. Echem ${ }^{\mathrm{c}}$, S. Prabhakaran ${ }^{\mathrm{d}}$, S. AnandKumar ${ }^{\mathrm{e}, 1}$, R.C. Barik ${ }^{\mathrm{a}, \mathrm{b}, *}$ \\ ${ }^{\text {a }}$ CSIR-Central Electrochemical Research Institute, Karaikudi, 630003, India \\ ${ }^{\mathrm{b}}$ Academy of Scientific and Innovative Research (AcSIR), Ghaziabad, 201002, India \\ ${ }^{\mathrm{c}}$ Department of Science Laboratory Technology, Ken Saro-Wiwa Polytechnic, Bori, Rivers State, Nigeria \\ ${ }^{\mathrm{d}}$ Department of Physics, School of Advanced Sciences, VIT University, Vellore, 632 014, Tamilnadu, India \\ ${ }^{\mathrm{e}}$ Department of Mechanical Engineering, Indian Institute of Technology Jammu, Jammu and Kashmir, 181 221, India
}

\section{A R T I C L E I N F O}

\section{Keywords:}

A. Copper

B. SEM

B. EIS

B. Laser

C. Corrosion

\begin{abstract}
A B S T R A C T
Besides electrochemical corrosion protection, laser shock peening provides extended fatigue life and mechanical properties for metals, as reported in the literature. However, most of the studies were performed under static conditions. The effectiveness of this method under flow conditions and prolonged immersion duration is addressed in this study. Copper discs were peened with Nd: YAG laser in the presence of $\sim 2$ mm thickness of water and polyvinyl chloride to absorb the intensity and provide residual stress without surface damage. Electrochemical and hydrodynamic analyses indicate that the peened surface showed higher corrosion resistance in $3.5 \% \mathrm{NaCl}$ compared to the unpeened.
\end{abstract}

\section{Introduction}

The material surface plays a major role in the electrochemical response and engineering applications. Therefore, surface modifications are conducted for a wide range of reasons including the improvement of physical, chemical, and mechanical properties. This follows the fact that the quality and performance of a metallic product can be directly correlated to its surface integrity achieved from different surface treatment processes carried out during production [1,2]. Several methods of surface modification techniques are in practice such as mechanical attrition, hot and cold rolling, high-pressure torsion, ball milling, mechanical shot peening, and laser shock peening to improve the surface microstructure, mechanical strength, corrosion resistance and tribological properties of the metallic material [3-6]. The surface treatment process focused on the present research is the laser shock peening (LSP) used for the improvement of corrosion protection and fatigue life of metals [7-9]. LSP is preferred to the rest of the processes because of its consistency in results and high-quality surface finish [10-12]. Application of laser light on material surfaces is an age-long process; however, LSP is a recently developed advanced surface modification technology that has been very effective in improving wear resistance, hardness, and corrosion resistance of metallic materials. It is a cold working process where pulses hit the metal surface through a high power intensity laser; generating shock waves that propagate through the metal to a certain depth ( $\sim 0$ to $2 \mathrm{~mm}$ ) depending on the power density applied [3]. The basic mechanism involved in this process is to create a compressive residual stress on the material which helps to delay premature failures. The compressive residual stress is seen to be responsible for the modification of the microstructure and improvement of the surface hardness and corrosion resistance. [13-15].

In addition to the improvement of electrochemical corrosion resistance and fatigue life, laser shock peening was found to be very useful in the enhancement of the metal resistance to stress corrosion cracking (SCC) and grain boundary refinement. Consequent to the grain boundary refinement, reduction in defects such as porosity and micro-cracks were also observed, these in turn reduce the oxygen diffusivity to the metal substrate when LSP treatment is applied on the surface $[9,16,17]$. Mahdavi et al. [8] investigated the effects of LSP on the electrochemical corrosion and microhardness properties of ANSI $316 \mathrm{~L}$ stainless steel alloy. Comparing the untreated and treated samples, it was found that

\footnotetext{
* Corresponding author at: CSIR-Central Electrochemical Research Institute, Karaikudi, 630003, India.

E-mail address: rakesh@cecri.res.in (R.C. Barik).

1 Current address: Processes and Engineering in Mechanics and Materials (PIMM) Laboratory, ENSAM, CNRS, Paris 75013, France.
} 
surface hardness improved by $35 \%$ while the corrosion protection performance increased by $100 \%$ for the treated samples in $3.5 \% \mathrm{NaCl}$ solution. In another development, the corrosion resistance of a biodegradable metallic implant (magnesium-calcium alloys) treated by LSP showed an increase in corrosion resistance by more than a 100 -fold in simulated body fluid electrolyte as reported by Guo et al. [18]. Similarly, Zhang et al. [19] reported a wide positive shift in the corrosion potential of nickel-titanium alloy from $-440 \mathrm{mV}$ to $-80 \mathrm{mV}$ (a difference of -360 $\mathrm{mV}$ ) and reduction in corrosion current density from 1.41 to $0.67 \mu \mathrm{A}$ $\mathrm{cm}^{-2}$ for the untreated and the LSP treated surfaces respectively, tested in a simulated body fluid. This result by Zhang group was accompanied by an increase in hardness value from 226 to $261 \mathrm{HV}$ due to the LSP treatment.

Further investigation was carried out by Vijayalakshmi et al. [7] on the effects of laser shock peening (LSP) on titanium alloy (Grade 5-Ti6Al4V) to establish the best set of LSP parameters for the enhancement of surface characteristics of the alloy. The result shows an excellent mechanical property for the peened surface compared to the unpeened. The experiment optimized the parameters such as power density ( $3 \mathrm{GW} / \mathrm{cm}^{2}$ ), wavelength $(532 \mathrm{~nm})$, and pulse overlap (60 \%) for titanium alloy. The rate of corrosion was found to be least at these sets of parameters due to low roughness and surface oxide layer which holds the fluctuation in current density with respect to potential. Liu et al. [16] demonstrated a repair method for fatigue damage using LSP in which they reported both improvement in fatigue life and healing effect on the copper film. Yujie et al. [20] showed that the distribution of grain size becomes more uniform and smaller near the top copper surface after LSP treatment. In addition, grain refinement was observed for copper along the normal (depth) direction [21,22]. Kim et al. [23] recently investigated the effect of laser shock peening on the fretting resistance of copper used for electrical components in automobiles. In their experiment surface hardness was improved from 55 to $120 \mathrm{HV}$ for the unpeened and peened copper respectively. The wear loss of the base metal was decreased from $1.61 \times 10^{-3} \mathrm{~mm}^{3}$ to $0.94 \times 10^{-3} \mathrm{~mm}^{3}$. Thus, the laser shock-peened copper maintained a low electrical contact resistance throughout the fretting test. Electrical contacts in automobiles usually fail due to wear arising from the small amplitude of reciprocal motion and blockage by corrosion products in the presence of air and moisture. However, the electrochemical corrosion behaviour of the treated copper surface was not investigated in this experiment. Moreover, despite these improvements in the use of LSP on metal protection, all the previous LSP corrosion analyses were performed under static conditions.

Therefore, the present research focused on the electrochemical and hydrodynamic flow characterization of the corrosion resistance and protection persistence of laser peened copper in $3.5 \% \mathrm{NaCl}$ medium. The present investigation will explore the effect of exposure time and hydrodynamic flow on the peened and unpeened surfaces. Following the fact that among a large number of adverse environments for corrosion such as salinity, dissolved oxygen, $\mathrm{pH}$, temperature variation, etc. flow environment has one of the highest destructive impacts on material loss and degradation [24-28]. This is important as LSP is fast becoming adopted in the area of corrosion protection, though it does not stand as a replacement to other corrosion protection methods in the literature. This is because the application of each method is defined by the peculiarity of the environment and nature of the management process involved. Laser shock peening is mainly targeted at aerospace, automobile, and marine environment components. In such environments, the use of inhibitors, conducting polymers, and self-assembly monolayer (SAM) of corrosion inhibiting compounds can not be applied even when they are economically more affordable. Laser shock peening has an advantage, as it can be applied to almost all metallic material for different aggressive environments. Therefore, validating the performance of LSP on copper corrosion protection in the flow environment becomes imperative not only to fill the knowledge gap but also for quality corrosion protection performance of copper and its alloys. This will provide a qualitative and quantitative assessment of this method for its proper application on metal corrosion protection especially where other methods such as corrosion inhibitors [29-31], may not be applicable. The present study will be compared to the corrosion protection efficiencies of the other methods in the literature. The electrochemical parameters that define metal stability in the corrosive media will be compared to ascertain the level of progress made. It is worthy to mention that the proposed LSP process is cost-effective especially at industrial scale since the same laser source can be used for a large number of products. It is easily applicable by simply shinning the laser light on the metal surface and environmentally friendly since the biological hazard can only occur at exposure such as a direct incident of laser on eye or skin and this can be managed through the laid down protocols [32].

\section{Experimental procedure}

\subsection{Metallic sample preparation (laser shock peening)}

Laser shock peening (LSP) experiment was performed by directing a low energy Nd: YAG laser (Litron lasers, UK) on a $1 \mathrm{~cm}^{2}$ polished $\mathrm{Cu}$ disc after covering with polyvinyl chloride (PVC) tape of $\sim 1 \mathrm{~mm}$ thickness. The surface was submerged in a thin layer of flowing water $(\sim 2 \mathrm{~mm})$ to further control the laser intensity [33,34]. Some authors preferred to use only flowing water without a covering or coating sub-layer thus they termed the peening process as laser shock peening without coating (LSPWC) [3,6]. The LSPWC allows a higher intensity of the laser light to hit the metal surface unlike the coated or covered one. This has a consequence of increasing the surface roughness and thermal effects, so we decided to use the covering method for the present work to minimize these problems. The Cu surface was thus covered with polyvinyl chloride tape in the present method as earlier stated. Therefore, the peening process was termed as laser shock peening with polyvinyl chloride (LSPVC). This term will be used throughout the discussion of this work.

The LSPVC optimization was carried out using the design of experiments (DoE) by tunning the laser energy and the overlap percentages as tabulated in Table 1. Also, the study investigated the sacrificial opaque layers of PVC tape at high, low, and medium power density and percentage overlap as used in the experiment. The energy consumption for the laser is varied with a pulse duration of $10 \mathrm{~ns}$ delivered with a spot diameter of $0.8 \mathrm{~mm}$ and with a wavelength of $1064 \mathrm{~nm}$. The maximum available repetition rate of $10 \mathrm{~Hz}$ was used for the whole LSPVC process. The exhibited radiance density (laser beam brightness) was $345.04 \mathrm{~mW}$. $\mathrm{mm}^{2} \cdot \mathrm{Sr}^{-1} . \mu \mathrm{m}$. The laser comprised of an $M^{2}$ value of 2 and a beam divergence of $0.5 \mathrm{mrad}$. The beam shape was of a top-hat profile [35, 36]. The electrical dryer was used to protect the lens from the water spilling during the LSPVC process. A 2D (XY) translation motorized stage (SVP Lasers, India) was employed to perform the LSPVC experiments in transverse and longitudinal directions.

\subsection{Microstructural characterization}

The phase structure and crystal orientation were investigated by $\mathrm{X}$ ray diffraction (XRD) using a Brucker diffractometer with $\mathrm{Cu}-\mathrm{K} \alpha$ radiation $(\lambda=1.54056 \AA)$ as a source. The scan was carried out at $2 \theta$ range from $30^{\circ}-85^{\circ}$ at the scan rate of $5^{\circ}$ per minute. The surface roughness, topography, and morphology were examined by atomic force microscopy (AFM, Nanosurfeasycan 2, Switzerland) and scanning electron microscope (Zeiss SEM instruments). The water droplet contact angle $(\theta)$

Table 1

Design of the experiments (DoE) for LSPVC optimization.

\begin{tabular}{lllll}
\hline Sample No & Power density $\left(\mathrm{Gw} / \mathrm{cm}^{2}\right)$ & Description & Overlapping (\%) & Mask \\
\hline 1 & 4 & Low & 40 & PVC \\
2 & 6 & Medium & 70 & PVC \\
3 & 8 & High & 50 & PVC \\
\hline
\end{tabular}


was measured on the peened and unpeened specimen using a goniometry instrument (Model Pheonix 300, SEO, Korea) at room temperature $\left(25^{\circ} \mathrm{C}\right)$. The droplet volume of $10 \mu \mathrm{L}$ distilled water was used to examine the surface wettability characteristics. Further, the mechanical properties of the compressed $\mathrm{Cu}$ surface were investigated at the nanoscale with the Nanoindentation instrument (Nano Test Vantage T61) from Micro Materials UK.

\subsection{Electrochemical measurements}

An Autolab Potentiostat (PGSTAT302) with three-electrode arrangements was used for electrochemical characterization. Platinum and saturated calomel electrodes (SCE) were used as counter and reference electrodes respectively, while the LSPVC peened Cu samples acted as the working electrodes. All the tests were carried out at room temperature using a $3.5 \% \mathrm{NaCl}$ electrolyte. Prior to all the electrochemical studies, the working electrode was introduced into the test solution and was allowed to attain a steady-state potential. Then a potential range of -0.3 to $+0.6 \mathrm{~V}$ vs. SCE was applied with scan rate at 1 $\mathrm{mV} / \mathrm{s}$. $E_{\text {corr }}$ and $I_{\text {corr }}$ were obtained from the potential $(E)$ vs. $\log j$ curves by the Tafel extrapolation method. EIS studies were carried out at static conditions for short and extended immersion time, thereafter; the hydrodynamic effect was investigated through electrochemical experiments carried out under flow conditions using a rotating cage (RC) instrument [24]. The initial frequency of $100 \mathrm{kHz}$, final frequency 10 $\mathrm{mHz}$, and AC sine wave amplitude perturbation of $10 \mathrm{mV}$ was applied at OCP. The impedance spectra were recorded with the unpeened and LSPVC peened $\mathrm{Cu}$ at different laser overlap percentages. All electrochemical experiments were replicated three times and all the potential values were measured with respect to SCE.

\section{Results and discussion}

\subsection{X-ray diffraction (XRD) analysis}

Fig. 1 shows the XRD patterns of the LSPVC treated Cu surfaces at 40, 50 , and $70 \%$ overlap in comparison with the unpeened surface. The results showed that the unpeened Cu exhibited three peaks observed at 2 $\theta \sim 44, \sim 51$, and $\sim 75^{\circ}$ indicating the characteristic peaks of $\mathrm{Cu}$ metal before LSPVC treatment. After the treatment, similar peaks were obtained in all the treated samples with minor changes observed on the (111) and (220) planes. This fact showed that there was neither formation of surface oxide or surface damage nor alteration of $\mathrm{Cu}$ crystal

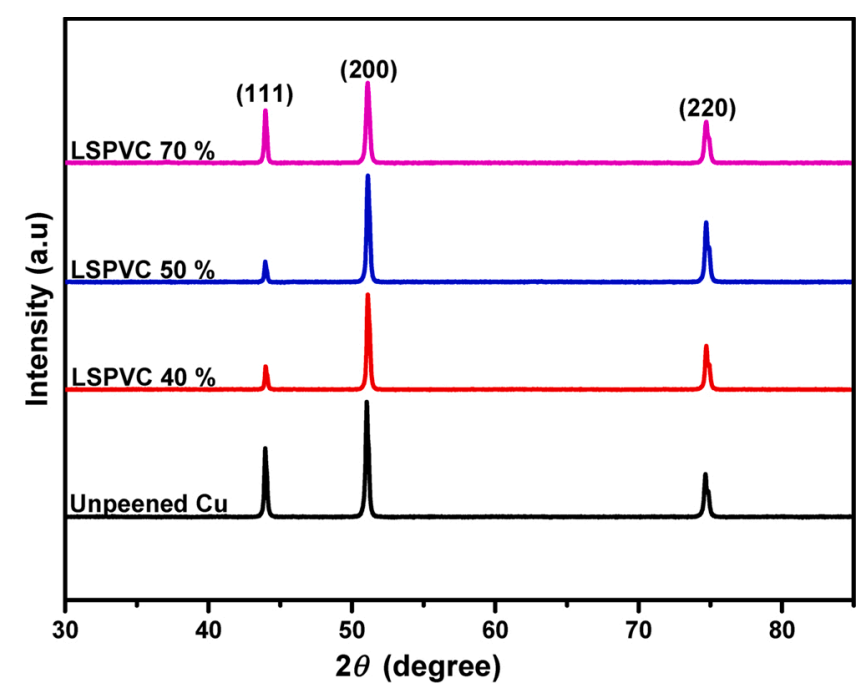

Fig. 1. XRD patterns of the unpeened and LSPVC peened Cu surface at 40,50 and $70 \%$ overlap. structure in the course of LSPVC treatment. A clear observation of the (111) plane showed little diminished intensity at 40 and $50 \%$ overlap while $70 \%$ overlap showed effect at the (220) plane which could be signs of surface modification. Although XRD which normally gives information from the bulk sample may not provide enough information on the surface changes. Thus further analysis was done with the help of scanning electron microscopy (SEM) as presented in the following discussion.

\subsection{Scanning electron microscopy (SEM) analysis}

The images of the $\mathrm{Cu}$ samples were taken after laser treatment using the scanning electron microscope. Fig. 2 shows the micrographs of the unpeened $\mathrm{Cu}$ surface and the peened at 40,50 , and $70 \%$ laser overlap. These show clearly that there were surface impacts which were minimal at $40 \%$, high at $50 \%$, and moderate at $70 \%$, see Fig. $2 \mathrm{~b}$, c, and d respectively. As observed, the $40 \%$ overlap was minimally impacted by the laser light due to a reduced power density $\left(4 \mathrm{Gw} / \mathrm{cm}^{2}\right)$ with pulse overlap. $50 \%$ overlap shows high impact as depicted by the more pronounced surface dimples and compact shrinking attributed to the doubling of the laser power density to $8 \mathrm{Gw} / \mathrm{cm}^{2}$ at this overlap, whereas $70 \%$ overlap peened at $6 \mathrm{Gw} / \mathrm{cm}^{2}$ shows less formation of dimples compare to $50 \%$ overlap but depicks more local impact leading to surface shrinking and initiation of valleys. The optimization of these parameters was shown in Table 1 . The observed effects clearly show that power density has more impact on the surface changes than pulse overlap during the LSP process [8]. Remember that the Power density has to do with the laser energy while the pulse overlap is the number of packets of the laser light hitting the surface at a particular point in time. The combination of the effects of these two parameters gives the overall peening impact. In Fig. 2, all the peened surfaces showed impacts as a result of the compression of the top surface leading to the intertwining structures and inducement of compressive residual stress which in turn led to shrinking and dimples on the peened samples relative to the applied parameters. The viewed effects of the SEM analysis were clearly represented in Fig. 3, which shows the schematic representation of the residual stress and impact depth of the unpeened and LSPVC peened surface at 40,50 , and $70 \%$ overlap. This is to further show that the $40 \%$ overlap has low impact depth with shallow dimples, $50 \%$ showed multiple effects and more dimples while $70 \%$ shows fewer impacts but valleys of local and nonuniform laser effects [13,37].

\subsection{Contact angle analysis}

The contact angle analysis of the unpeened and LSPVC peened $\mathrm{Cu}$ surface at 40,50 , and $70 \%$ overlap measured at room temperature under atmospheric pressure is presented in Fig. 4. Contact angle measurement describes the surface energy and the wettability characteristics of a material. A given surface at a particular temperature and pressure has a unique equilibrium contact angle. If the water contact angle is smaller than $90^{\circ}$, the solid surface is considered hydrophilic and if the water contact angle is larger than $90^{\circ}$, the solid surface is considered hydrophobic. Fig. 4 shows that the contact angle value obtained for unpeened is $36.1^{\circ}$, whereas the peened surface shows $63.8^{\circ}$ for the $40 \%$, $90.3^{\circ}$ for $50 \%$, and $86.7^{\circ}$ for the $70 \%$ overlap. This indicates that the contact angles of the $\mathrm{Cu}$ surface increased with the increase in the laser overlap up to $50 \%$ and dropped at $70 \%$. Despite the increase, it was only the $50 \%$ overlap that effectively transformed from a hydrophilic surface to a hydrophobic one. At $70 \%$ overlap, there was a fall in the contact angle value due to reduced hydrophobicity may be a result of local valleys which increased the roughness. Since roughness enhances the wettability and surface chemistry, it, therefore, means that $90.3 \%$ contact angle of the peened surface shows that the surface roughness was not excessively increased by the laser treatment. The relationship between surface roughness, measured contact angle and the Young contact angle was explained using Wenzel correlation for a 

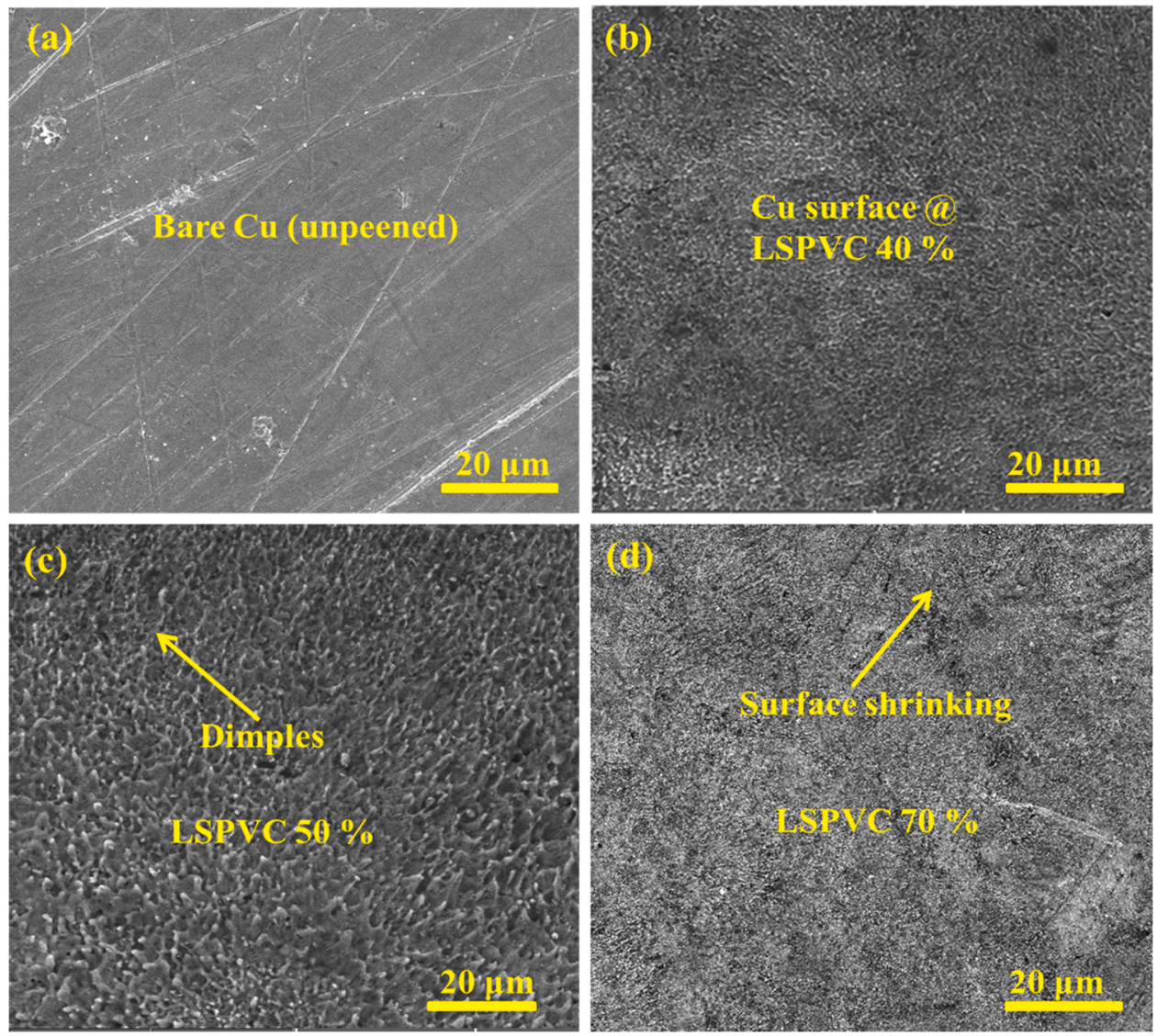

Fig. 2. SEM micrographs of the unpeened and LSPVC peened Cu surfaces (a) Unpeened bare $\mathrm{Cu}$ and the peened at (b) $40 \%$, (b) $50 \%$, and (c) $70 \%$ overlap.

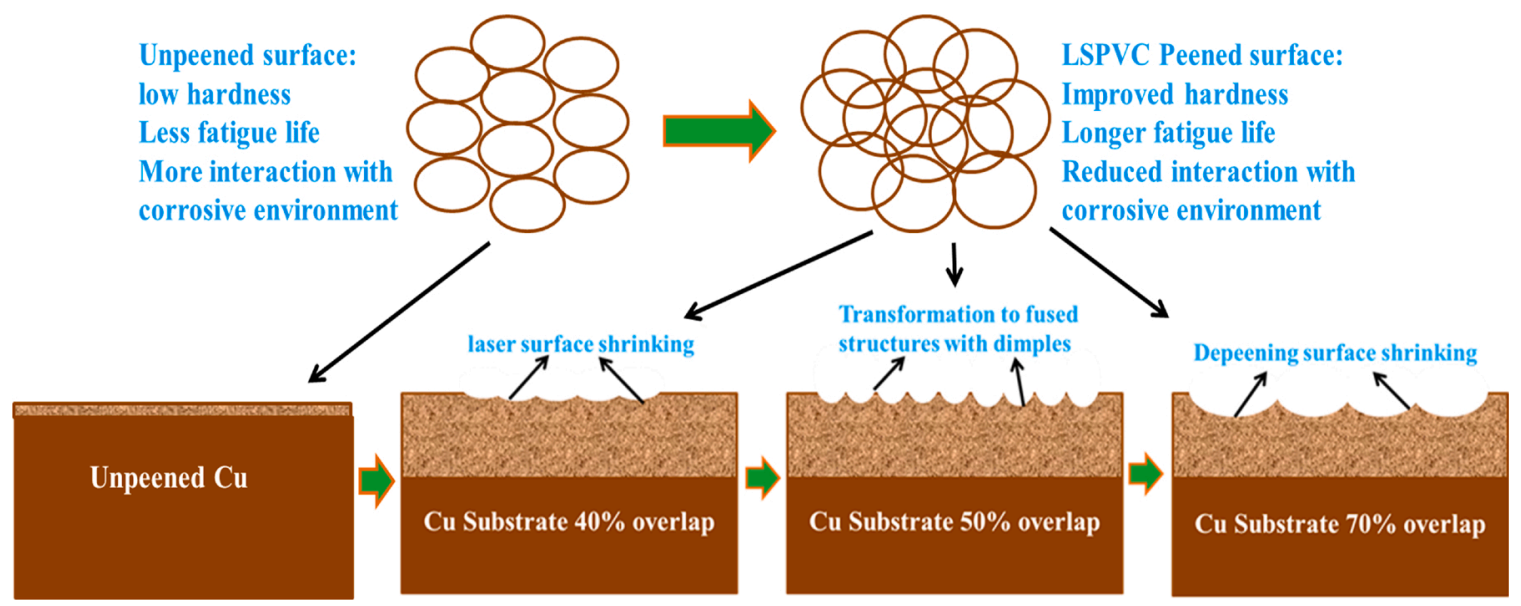

Fig. 3. Schematic representation of the Unpeened Cu surface compared to the LSPVC peened showing dimples, compact top layer, and the residual stress impact of the peened at 40,50 , and $70 \%$ overlap.

homogeneous surface in the following Eqn;

$\cos \left(\theta_{m}\right)=r \cos \left(\theta_{Y}\right)$

Where $\theta_{m}$ is the measured contact angle, $\theta_{Y}$ is the Young contact angle and $r$ is the roughness ratio. The roughness ratio is defined as the ratio between the actual and projected solid surface area [38-40].

\subsection{Analysis of mechanical properties}

Fig. 5 shows the nanoindentation data of the unpeened and LSPVC peened $\mathrm{Cu}$ surface at 40,50 , and $70 \%$ overlap. Fig. $5 \mathrm{a}$ is the hysteresis of the loading and unloading curves. The area bounded by loading and unloading curves defines the degree of resistance to plastic deformation. An increase in the area correlates to an increase in plastic deformation and vice versa [41]. In the present research, a $50 \%$ overlap showed the highest resistance to plastic deformation as indicated by the small area under the curve. Fig. $5 \mathrm{~b}$ shows the varying hardness values with laser overlap. The hardness of the unpeened bare $\mathrm{Cu}$ was $1.188 \mathrm{GPa}$, surprisingly higher than that of $40 \%$ peened which was found to be 1.025 GPa. This could be attributed to the generation of nanoparticles and contaminants at the metal surface at the beginning of the LSP process when the laser intensity is low [8]. This shows that at low laser overlap 


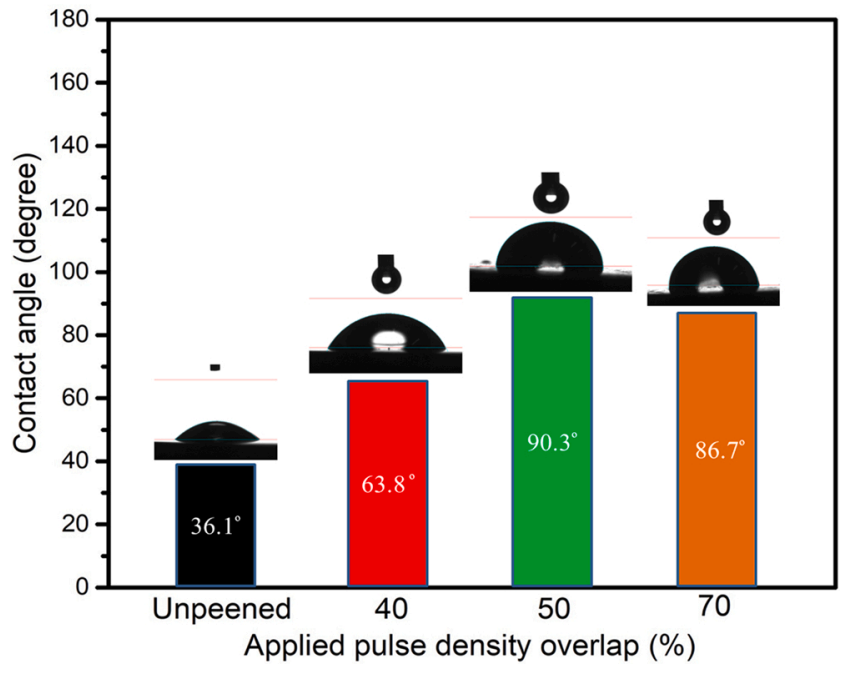

Fig. 4. Contact angle data of the unpeened and LSPVC peened $\mathrm{Cu}$ surface at 40, 50 , and $70 \%$ overlap measured at room temperature under atmospheric pressure.

and power density, the surface becomes poorly modified yielding surface products or pollutants of less hardness. At $50 \%$ overlap hardness increased to $2.597 \mathrm{GPa}$ while at $70 \%$ it was $1.522 \mathrm{GPa}$, indicating the presence of compressive residual stress on both samples. This shows that the optimum hardness was achieved at $50 \%$ where the power density had a good match with the overlap, below or above which there could be fluctuations in hardness due to mismatch of laser energy with overlap.

Moreover, residual stress was further studied in detail using the loaddepth curves. It is well known that the residual stresses significantly affect load-depth curves. Residual stress can be evaluated using indentation tests if the value of the hardness and the loading curve is higher than initial values after LSPVC processing; it indicates that compressive residual stress is present on the surface. If the hardness is lesser, then tensile residual stresses might be present $[33,42,43]$. The impact of residual stress on the load-depth curves was examined at different positions where the indentation depths were held constant (Fig. 5c). For example, at a constant depth of $700 \mathrm{~nm}$, it was obvious that the curves rose according to their compressive residual stress with the $50 \%$ overlap showing the highest residual stress. This is in line with the report in the literature that the compressive stress can constrain the indentation plasticity, thus leading to a higher indentation load than that for the stress-free state where less load was required for the same indentation depth [44]. On the other hand, holding the load constant shows similar trends for the effects of residual stress on the indentation depth Fig. $5 \mathrm{~d}$. Apart from the $40 \%$ overlap, it is clear from Fig. $5 \mathrm{~d}$ that the indentation depths shifted to the left in accordance with their residual stress. $50 \%$ shows the least indentation depth penetration. The relatively lower depth of penetration in the laser peened sample could be attributed to the enhanced hardness and compressive residual stress inducement. Therefore, it can be concluded from this experiment that residual stress does not increase indefinitely with the increase in the overlap but there exists an optimal value where the overlap together with the applied power density makes a good match as stated earlier, above or below this optimal value the laser light might not impact directly on the residual stress but can be converted to surface melting. Therefore, in general,
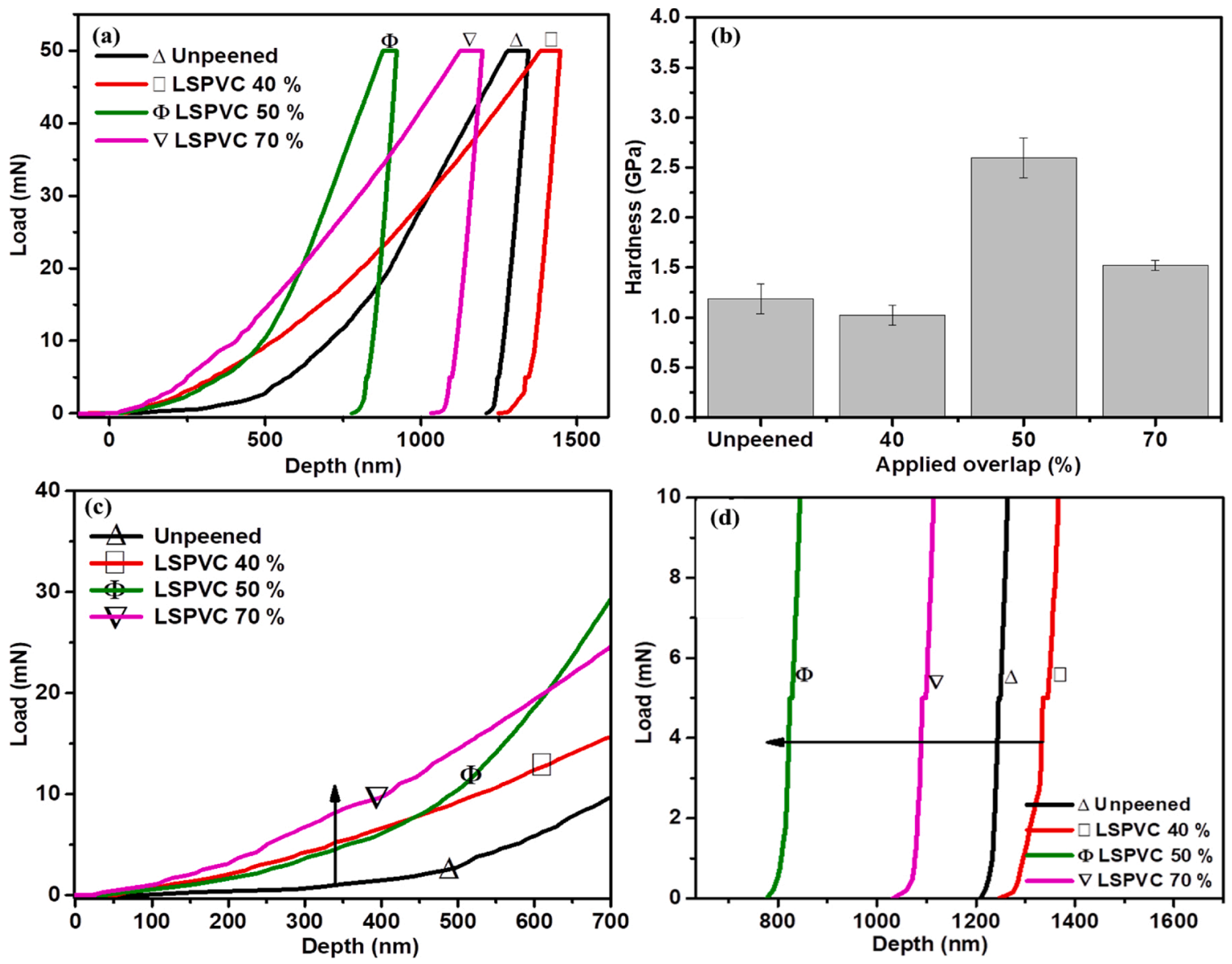

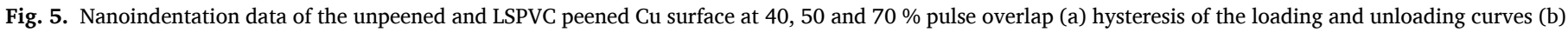
variation of hardness values with laser overlap, residual stress impacts on (c) loading curves at constant depths and (d) the indentation depth at constant loads. 
LSPVC induces compressive residual stresses and there is an optimal set of operating parameters for this condition to improve hardness and surface quality.

\subsection{Potentiodynamic polarization}

Prior to potentiodynamic polarization and other electrochemical measurements, the stability and free dissolution pattern of the unpeened and the LSPVC peened $\mathrm{Cu}$ surfaces was first monitored by potential measurement in the absence of current known as the open circuit potential (OCP). Fig. 6 shows the OCP, potentiodynamic polarization, and the corrosion rate curves for the unpeened and peened $\mathrm{Cu}$ surface at 40 , 50 , and $70 \%$ overlap; immersed in $3.5 \% \mathrm{NaCl}$ solution at room temperature. Fig. 6 a shows the variations in the OCP of the unpeened and peened samples with pulse laser overlap. The measurements were recorded for 1000s since all the peened samples showed stability with less than $0.001 \mathrm{~V}$ variation beyond $500 \mathrm{~s}$. LSPVC $50 \%$ showed potential decay from $-0.145 \mathrm{~V}$ to a final value of $-0.162 \mathrm{~V}$ vs. SCE. The other peened samples, show minimal changes with time, probably due to reduced roughness. Power density tends to increase surface hardness with a consequent increase in roughness [7]. But the advantage of the improved hardness outweighs that of the roughness in the long run for the metal protection. LSPVC 40 and $70 \%$ showed minor potential decay whereas the unpeened $\mathrm{Cu}$ surface showed potential decay from -0.29 to a final value of $-0.32 \mathrm{~V}$ vs. SCE, typical $E_{\text {corr }}$ of bare $\mathrm{Cu}$ surface in $3.5 \%$ $\mathrm{NaCl}[29,45]$. In all the plots, the free potential $\left(E_{\text {corr }}\right)$ of $\mathrm{Cu}$ tends positive with peening overlap with $50 \%$ overlap showing the highest positive value.

Fig. $6 \mathrm{~b}$ shows the potentiodynamic polarization curves for the unpeened $\mathrm{Cu}$ in comparison with the peened surfaces at 40, 50, and $70 \%$ overlap. The corrosion potentials obviously shift to more positive values from -0.323 to $-0.162 \mathrm{mV}$ at $50 \%$ overlap (equivalent to $49.9 \%$ increase). The corrosion current density reduced from 6.31 to $0.35 \mu \mathrm{A}$ $\mathrm{cm}^{-2}$, indicating that the best performance of the modifications is at this overlap applied at a power density of $8 \mathrm{Gw} / \mathrm{cm}^{2}$. However, looking at the curve due to LSPVC $50 \%$, the $E_{\text {corr }}$ is in the active dissolution region of the anodic part, which shows extensive Tafel behaviour indicating a high rate of corrosion at the onset before exhibiting a reduction in corrosion current. This could be the evidence of the potential decay witnessed in the OCP analysis, probably due to the roughened part of the surface by high power density [7], compared to the less impacted surface at 40 and $70 \%$ overlap with the lower power density of 4 and 6 $\mathrm{Gw} / \mathrm{cm}^{2}$ respectively. However, the power density effect on the LSPVC $50 \%$ could not overturn the overall performance in the reduction of the corrosion current density as the surface is at the same time hardened by the compressive residual stress arising from the higher laser power. Fig. $6 \mathrm{c}$ shows clearly the extent of performance of the entire modification process when the best performing sample (LSPVC $50 \%$ ) was compared to the unpeened surface. This can be ascribed to the compact high resistant surface due to the shrinking effect and grain refinement of the high powered laser light from LSP processing, [9]. The performance of the LSPVC modification at different overlaps was further analyzed quantitatively and presented in Table 2 . The trend of the parameters in Table 2 shows that the inhibition efficiency and the free corrosion
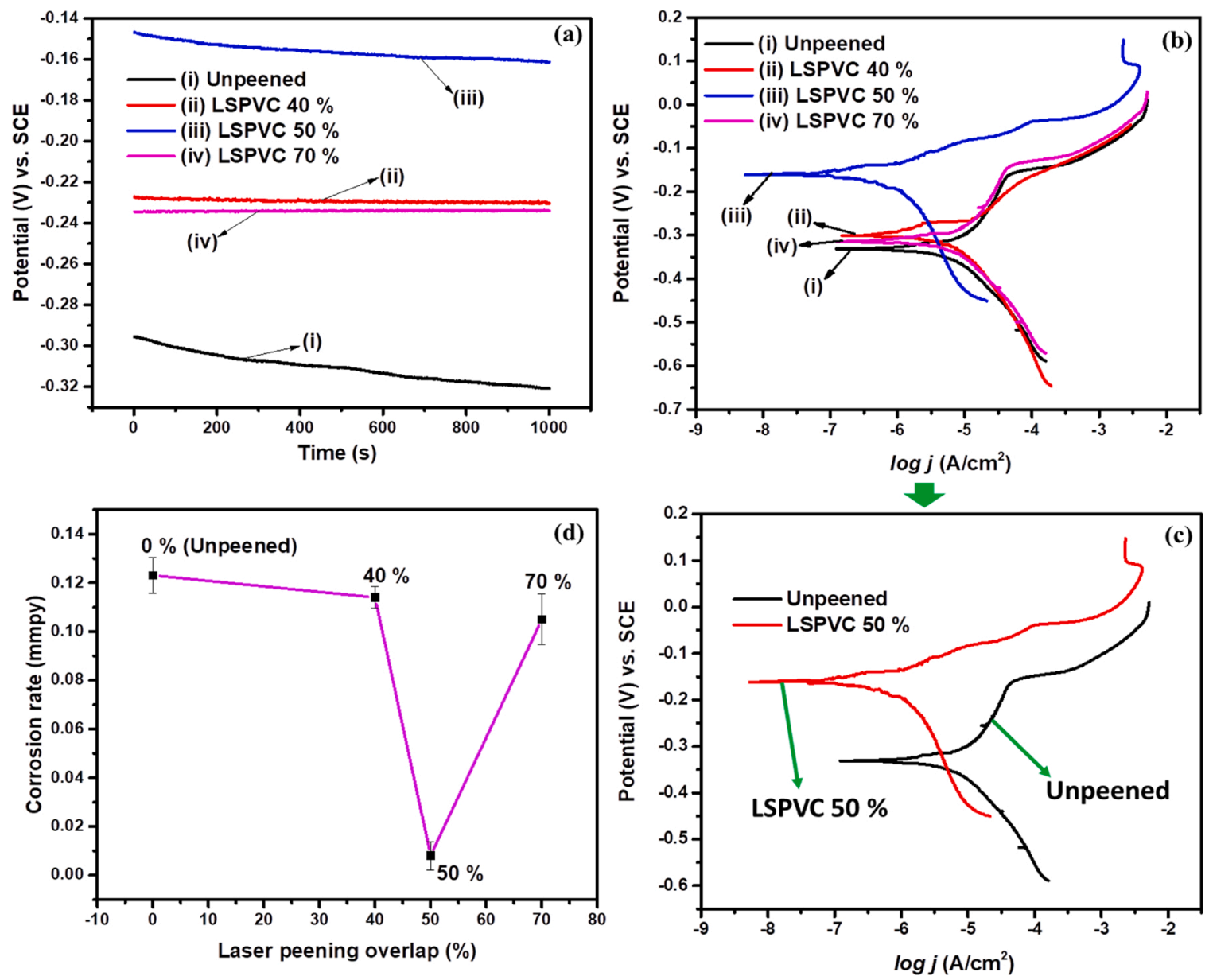

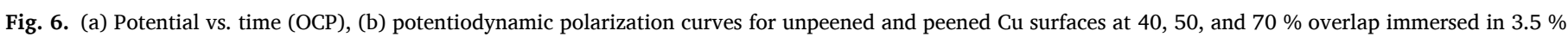

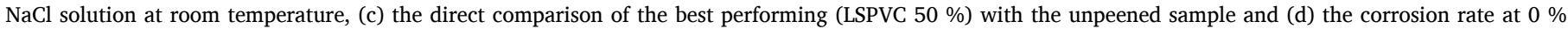
(unpeened), 40, 50 and $70 \%$ overlap. 
Table 2

Parameters related to the Potentiodynamic Polarization study of $\mathrm{Cu}$ immersed in $3.5 \% \mathrm{NaCl}$ for the unpeened and peened surface at 40, 50 and, $70 \%$ overlap at room temperature.

\begin{tabular}{lllllll}
\hline $\begin{array}{l}\text { LSPVC } \\
\begin{array}{l}\text { Overlap } \\
(\%)\end{array}\end{array}$ & $\boldsymbol{E}_{\text {corr }}\left(\mathrm{V}_{\mathrm{SCE}}\right)$ & $\begin{array}{l}\boldsymbol{I}_{\text {corr }} \\
(\mu \mathrm{A} \\
\left.\mathrm{cm}^{-2}\right)\end{array}$ & $\begin{array}{l}\boldsymbol{E}_{\text {corr }} \\
(\mathrm{mV} / \\
\text { decade) }\end{array}$ & $\begin{array}{l}\boldsymbol{\beta}_{c}(\mathrm{mV} / \\
\text { decade) }\end{array}$ & $\begin{array}{l}\text { Corrosion } \\
\text { rate } \\
(\mathrm{mmpy})\end{array}$ & $\eta(\%)$ \\
\hline Unpeened & -0.323 & 6.31 & 129.5 & 140.3 & 0.123 & - \\
40 & -0.304 & 2.40 & 94.5 & 136.2 & 0.114 & 61.97 \\
50 & -0.162 & 0.35 & 54.6 & 79.7 & 0.008 & 94.45 \\
70 & -0.313 & 1.54 & 106.7 & 120.7 & 0.105 & 75.59 \\
\hline
\end{tabular}

potential $\left(E_{\text {corr }}\right)$ increased in the positive direction while the corrosion current density and the corrosion rate decreased with an increase in laser percentage overlap. The trend further showed that the corrosion current density decreased with the increase in laser overlap with a minor deviation at LSPVC $70 \%$. The $50 \%$ peened has the lowest corrosion current density of $0.35 \mu \mathrm{A} \mathrm{cm}{ }^{-2}$. The corrosion rate was reduced from 0.123 to 0.008 mmpy with corrosion protection efficiency of $94.45 \%$ as calculated from the $I_{\text {corr }}$ value for LSPVC $50 \%$. The trend in all the parameters in Table 2 indicates the effective protection of $\mathrm{Cu}$ in $3.5 \% \mathrm{NaCl}$ by the LSPVC process. The potentiodynamic data in Table 2 were obtained from Tafel extrapolation of the just discussed $E$ vs. $\log j$ curves of Fig. 6b. We can see clearly that the copper electrode immersed in a $3.5 \%$ $\mathrm{NaCl}$ solution exhibits a typical Tafel behaviour in both the anodic and cathodic parts $[46,47]$. The cathodic parts were not clearly limited by oxygen diffusion but still display a Tafel behaviour with the corrosion current increasing proportionally with the potential (see Fig. 6b), typical behaviour of copper in $\mathrm{NaCl}$ system $[48,49]$. It is known from the literature that the extrapolation of both anodic and cathodic sides gives more accurate values of the potentiodynamic parameters thus was applied in this study $[9,46]$. The extrapolation of the pair of Tafel regions in the curves and the corrosion rates were accurately determined using the Ec-lab corrosion software model 10.40 . The condition is that the Tafel region must be linear for at least one decade of current after a potential scan of about $\pm 300 \mathrm{mV}$, and is taken within $50-100 \mathrm{mV}$ above and below the $E_{\text {corr }}$ [50]. The current value at the $E_{\text {corr }}$ intersection is then the corrosion current $\left(I_{\text {corr }}\right)$, directly called the corrosion current density when the working electrode (WE) is a standard $1 \mathrm{~cm}^{2}$ surface area. Other values of the WE area must be used to divide the measured equilibrium corrosion current to obtain the corrosion current density $\left(I_{\text {corr }}\right)$ according to the following equation [50].

$I_{\text {corr }}=I_{e q} / A_{W E}$

Where $I_{e q}$ and $A_{W E}$ are the measured equilibrium corrosion current and the $\mathrm{WE}$ area respectively.

From the corrosion current density, the protection efficiency $(\eta \%)$ of the peened surfaces were determined against the unpeened, according to the inhibitory efficiency formula, Eq. 3.

$\eta \%=\frac{I u_{\text {corr }}-I p_{\text {corr }}}{I u_{\text {corr }}} \times 100$

Where $I u_{\text {corr }}$ and $I p_{\text {corr }}$ are the corrosion current densities of the unpeened and the peened surfaces respectively.

The electrochemical results are further depicted in the plot of the corrosion rate versus percentage overlap of the different modifications compared to the zero modified surface (unpeened $\mathrm{Cu}$ ) in Fig. 6d. This shows that there was a tendency to reduce the corrosion rate in all the laser peened samples in comparison to the unpeened $\mathrm{Cu}$, whereas the highest performance in corrosion rate reduction was found at LSPVC 50 $\%$. The results not only confirm that the LSP modification is optimum at LSPVC $50 \%$ but also showed that the LSP process is an effective method for $\mathrm{Cu}$ corrosion mitigation [7,9,19,51].

\subsection{EIS analysis}

The electrochemical impedance plots for peened and unpeened $\mathrm{Cu}$ surface immersed in $3.5 \% \mathrm{NaCl}$ solution at room temperature under static conditions are presented in Fig. 7. Fig. 7a shows the Nyquist plots for the unpeened and peened $\mathrm{Cu}$ surfaces at different modifications of 40, 50, and $70 \%$ pulse overlap. The diminished impedance capacitive loop for the unpeened is shown in the inset of Fig. 7a. This shows that there was a large improvement in the corrosion resistance of all the laser modified surfaces. The peened samples show an increased diameter of the impedance capacitive loops due to enhanced corrosion performance. The Nyquist plots exhibit a single capacitive loop implying that the corrosion of the peened samples is mainly charge transfer controlled (i.e. charge transfer is the slowest process) from the surface to the electrolyte through the shrunk compact $\mathrm{Cu}$ surface [52,53]. The resistance increased with an increase in the laser percentage overlap and the applied power density. LSPVC $50 \%$ showed the highest corrosion resistance, due to the high impact of laser power density which optimized at $8 \mathrm{Gw} / \mathrm{cm}^{2}$ with a $50 \%$ overlap. This is in line with the improved hardness and compressive residual stress as observed from the indentation results (Fig. 5) [7]. At LSPVC $70 \%$ there was a decrease in the corrosion resistance which could be attributed to a mismatch of power density and the percentage overlap as the surface behaviour is dependent on the interplay of the overlap and power density inputs as shown in Table 1. This could also be attributed to an increase in local roughness as witness in this sample by the aid of SEM [8]. Fig. 7b and c are the Bode modulus and phase angle plots which are also in line with the Nyquist plot data, the LSPVC $50 \%$ shows the highest impedance modulus and phase angle value of all the modifications and the unpeened $\mathrm{Cu}$ surface.

Fig. 8 showed the equivalent circuits fit for the quantitative analysis of the systems which could be grouped into two, Fig. 8a was used to fit all the plots except those with Warburg impedance $(W)$ (see plots of unpeened bare $\mathrm{Cu}$, inset of Fig. $7 \mathrm{a}$ and $0 \mathrm{~h}-228 \mathrm{~h}$ of Fig. 9b) which were fitted into the circuit of Fig. 8b. These circuits depict the electrical components of the physical parameters of the working electrode and the solution system. The solution medium shows the solution resistance $R_{s}$ to the movement of ions and species in solution. The surface of the electrode exhibited high charge transfer resistance $\left(R_{c t}\right)$ due to LSPVC peening. $R_{f}$ represents the film resistance developed on the Cu surface after peening process and during immersion as a barrier accumulated between the metal and the aggressive medium interface. The major effect of the peening process is not the development of film but to induce residual stress which makes the surface compact and thus the $R_{c t}$ was improved tremendously $[7,8]$. The overall resistance of the system is expressed as the polarization resistance $\left(R_{p}\right)$ which is the combination of the $R_{f}$ and $R_{c t}$. Further the data showed two non-ideal capacitances represented as constant phase element (CPE1) arising from the film/solution interface and (CPE2) for the double layer capacitance due to surface inhomogeneity between the metal and the surrounding film. The $Y_{1}$ and $Y_{2}$ are the magnitudes of the constant phase elements corresponding to the $\mathrm{CPE}_{1}$ and the $\mathrm{CPE}_{2}$ for the film and the metal suface respectively. The dispersion coefficients $n_{1}$ and $n_{2}$ showed value Table 3 less than unity as an indication for the film imperfection due to roughness and porosity, see Table 3, [54,55].

The quantitative values of the charge transfer resistance $\left(R_{c t}\right)$ and other electrochemical impedance parameters related to the unpeened and the different peened samples are presented in Table 3 which were generated from electrochemical circuit fit carried out using Zsimpwin 3.21. It is clear from Table 3 that LSPVC $50 \%$ shows the highest $R_{c t}$ value, $17,020 \Omega$. $\mathrm{cm}^{2}$ compared to $957 \Omega . \mathrm{cm}^{2}$ of the unpeened, however, there was increasing trend in the $R_{c t}$ with laser overlap. The value of film resistance $\left(R_{f}\right)$ in Table 3 is relatively small probably because the major resistance portion is arising from surface compressive residual stress which contributed more to the improvement of $R_{c t}$ of $\mathrm{Cu}$ through 

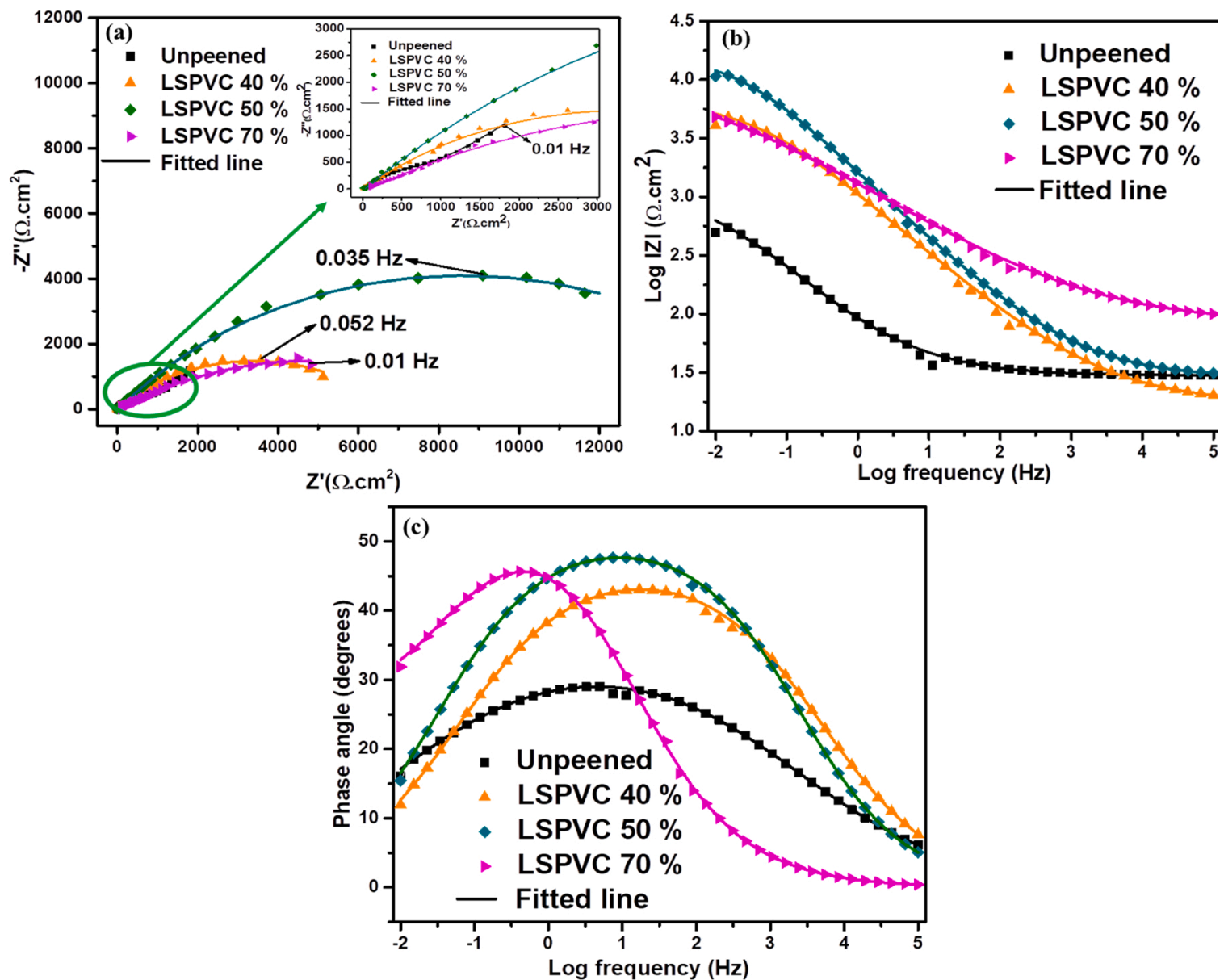

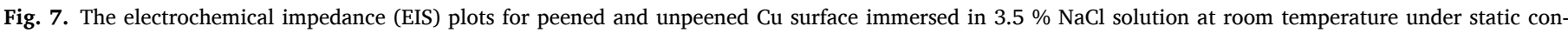
ditions: (a) the Nyquist, (b) Bode modulus, and (c) Bode phase angle at $0 \%$ (unpeened), $40 \%$, $50 \%$, and $70 \%$ overlap.

the shrunk surface, thus, minimal film formation was observed [8]. Overall film resistance of the LSPVC peened samples is greatly enhanced compared to the unpeened specimen [7]. The $Y_{1}$ and $Y_{0}$ showed decrease in trend with increase in laser overlap see Table 3, confirming the improvement of the surface resistance to water penetration due to the surface compactness. In addition, the dispersion coefficient $(n)$ increased with increase in overlap percentage as well, this is in line with improved corrosion protection behaviour of the $\mathrm{Cu}$ surface in the aggressive medium by the LSPVC process. The chi square $\left(\chi^{2}\right)$ values in Table 3 further validates the minimal error margine in the electrochemical circuit fit since the values are only little above $1 \times 10^{-3}$. All these amount to the protection efficiency ( $\eta \%$ ) of $94.38 \%$, from EIS, calculated using Eqn. 3 and is in good agreement with the potentiodynamic result in the previous discussion.

$\eta \%=\frac{R_{p c t}-R_{u c t}}{R_{u c t}} \times 100$

Where, $R_{p c t}$ and $R_{u c t}$ are the charge transfer resistances of the peened and unpeened surfaces respectively.

Therefore, to further investigate the efficacy of this method on $\mathrm{Cu}$, electrochemical impedance spectroscopy was carried out to determine the effect of extended immersion time and flow in the corrosive environment of the same electrolyte $(3.5 \% \mathrm{NaCl})$, the results are presented in Fig. 9. This experiment was performed with best performing sample (LSPVC $50 \%$ ) in comparison with unpeened $\mathrm{Cu}$. The Nyquist plots of the LSPVC $50 \%$ peened and the unpeened $\mathrm{Cu}$ surface are shown in Fig. 9a and $\mathrm{b}$ respectively at different immersion durations from $0 \mathrm{~h}$ to $304 \mathrm{~h}$ (12 days plus 6 h).The overall impedance results showed a reduction in
$R_{c t}$ for both systems (peened and unpeened) during long immersion duration compared to the previous results of Fig. 7. This is definitely due to prolonged corrosion attack in the presence of chloride ion $\left(\mathrm{Cl}^{-}\right)$. The increasing tendency of the $R_{c t}$ with immersion time in Fig. 9a and 9b could be attributed to concentration polarization resulting from accumulated corrosion products since by extending the immersion duration the resistance became lower than the original value but regained some resistance as time progressed further. It is interesting to note that despite the exposure for long time duration the LSPVC $50 \%$ peened still showed evidence of better performance compared to the unpeened which showed drastic fall in the $R_{c t}$ values with time as clearly shown by Fig. 9c. The results conclude that the LSPVC surface modification is capable of providing long-time protection for $\mathrm{Cu}$ metal in the corrosive chloride medium. Further, the samples were exposed to a flow environment of the same corrosive electrolyte $(3.5 \% \mathrm{NaCl})$ to investigate the hydrodynamic effect on the performance of the peened samples in comparison to the unpeened. This is very crucial since the corrosion attack is often more aggravated by hydrodynamic flow than the static systems. Fig. $9 \mathrm{~d}$ presents the representative results of the hydrodynamic experiments at different flow rates of 120,240 , and $360 \mathrm{rpm}$. The results revealed the stable nature of the LSPVC $50 \%$ compared to the unstable bare unpeend $\mathrm{Cu}$ surface. This was indicated by the gradual reduction in the $R_{c t}$ by the peened at all the rotation speeds $(120,240$ and $360 \mathrm{rpm})$ as a result of flow effect whereas in the case of the unpeened there was a drastic rise in the $R_{c t}$ at $240 \mathrm{rpm}$, probably due to formation of corrosion products and its sudden fall at $360 \mathrm{rpm}$ as the corrosion products probably get transported away from the surface as a result of flow. In chloride medium $\mathrm{Cu}$ system, $\mathrm{CuCl}$ corrosion product is insoluble and can 


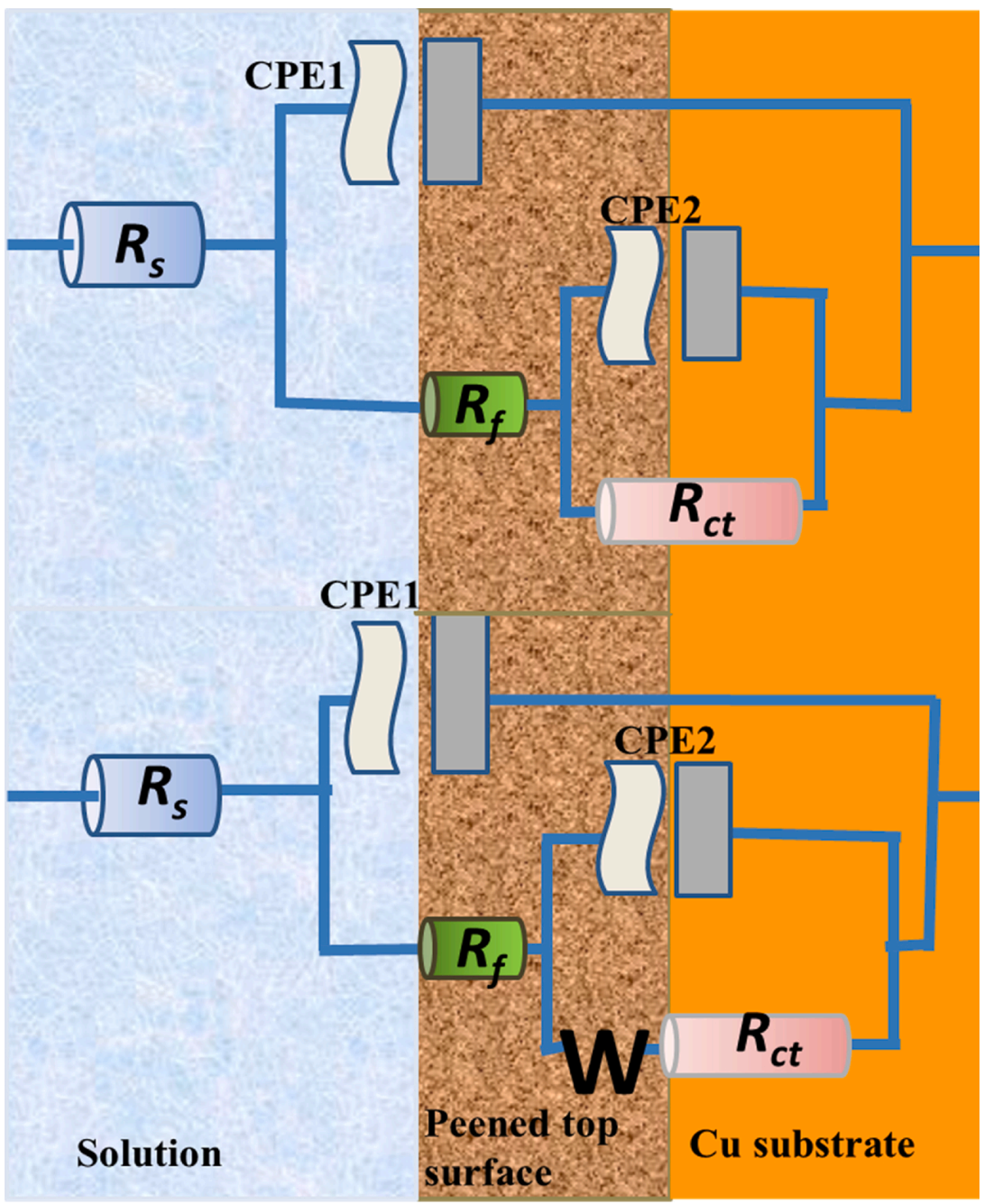

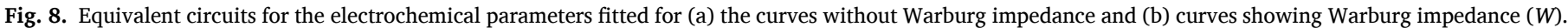

be easily adsorbed on the surface. However, the adhesion of $\mathrm{CuCl}$ (formed as a result of the reaction in Eq. 5) to the copper surface is not sufficient to protect the copper from further corrosion. In the second part of the reaction in Eq. 6, the $\mathrm{CuCl}$ is transformed into a soluble copper (I) chloride complex [56], which can easily diffuse into the bulk of the solution especially by the aid of the flow medium. All the electrochemical experiments, therefore, prove the better performance of the peened surface compared to the unpeened.

$$
\begin{aligned}
& \mathrm{Cu}+\mathrm{Cl}^{-} \rightleftarrows \mathrm{CuCl}+\mathrm{e}^{-} \\
& \mathrm{CuCl}+\mathrm{Cl}^{-} \rightleftarrows \mathrm{CuCl}_{2}^{-}
\end{aligned}
$$

\subsection{SEM analysis before and after extended immersion duration}

The surface morphology and the extent of corrosion damage before and after the extended immersion duration for the peened (LSPVC $50 \%$ ) and unpeened samples were viewed by the aid of scanning electron microscope (SEM) and the results are presented in Fig. 10. Fig. 10a and b are the unpeened bare $\mathrm{Cu}$ before and after long-duration immersion respectively. The bare $\mathrm{Cu}$ after corrosion showed a high rate of degradation and surface damage with deposits of corrosion products. This could be due to the direct interaction of the unpeened $\mathrm{Cu}$ surface with the aggressive chloride medium for an extended immersion period which made the corrosion impacts more evident as observed in Fig. 10b. Whereas, in the case of the LSPVC $50 \%$ peened $\mathrm{Cu}$, Fig. 10c and d, represent the surface before and after long-duration exposure to chloride medium respectively. The peened surface before immersion (Fig. 10c) showed a different morphology compared to the bare unpeened $\mathrm{Cu}$ (Fig. 10a), due to the peening effect. Fig. 10c thus showed surface shrinking, dimples, and intertwining of the physical structures therein, due to laser shock effect. This resulted in the stabilization of the peened Cu surface (Fig. 10d) as it showed virtually no corrosion damage unlike the unpeened. Fig. 10e and $f$ are the digital images of the unpeened and the peened respectively, after long-duration exposure to the chloride medium showing a physical view of the same surfaces previously imaged with SEM in Fig. 10b and d. This clearly showed the real-life damage due to aggressive chloride medium attack. The damage on the unpeened surface is so severe with an indication of a localized micro gully due to the concentration of metal loss in the absence of peening treatment as captured by both SEM and camera imaging. In the case of the LSPVC 50 $\%$ peened surface after immersion for $304 \mathrm{~h}$ (12 days $6 \mathrm{~h}$ ), the surface was intact with minimal localized pit damage. These analyses are in agreement with the SEM and conclude that the LSPVC treatment by the laser light has modified the surface into an unpenetrable one by $\mathrm{Cl}^{-}$ through the shock shrinking process which leaves it as compressed permanent stress.

\subsection{SEM analysis before and after flow corrosion}

Fig. 11 shows the SEM micrographs of the unpeened (Fig. 11a-d) and the peened (Fig. 11e-h) before and after flow corrosion at the rotation speeds of 120, 240 and $360 \mathrm{rpm}$. The SEM results are in line with the 

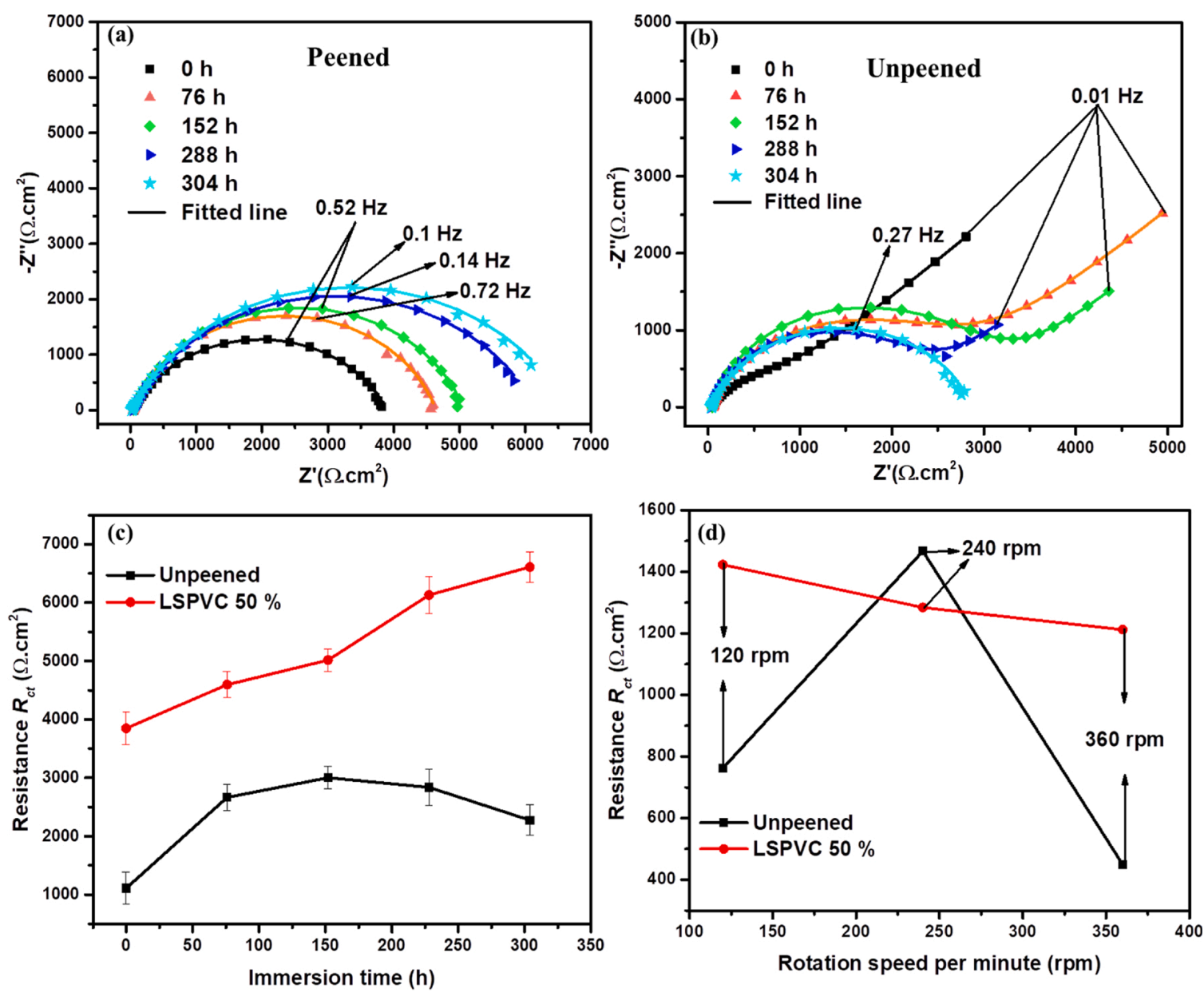

Fig. 9. The EIS data for the selected LSPVC $50 \%$ and the unpeened $\mathrm{Cu}$ surface immersed in $3.5 \% \mathrm{NaCl}$ solution at room temperature, (a, b) Nyquist plots for $50 \%$ peened and unpeened Cu respectively, (c) change in the charge transfer resistance $\left(R_{c t}\right)$ with immersion time, under static conditions at extended immersion duration, and (d) comparison of $R_{c t}$ with rotation speed at 120, 240 and $360 \mathrm{rpm}$ for the experiments under hydrodynamic conditions.

Table 3

EIS Parameters of $\mathrm{Cu}$ in $3.5 \% \mathrm{NaCl}$ obtained for the unpeened and peened surface at 40,50 and, $70 \%$ overlap at room temperature.

\begin{tabular}{|c|c|c|c|c|c|c|c|c|c|c|}
\hline \multirow{2}{*}{ LSPVC Overlap (\%) } & \multirow{2}{*}{$\boldsymbol{R}_{s}\left(\Omega . \mathrm{cm}^{2}\right)$} & \multirow{2}{*}{$\boldsymbol{R}_{f}\left(\Omega \cdot \mathrm{cm}^{2}\right)$} & \multicolumn{2}{|c|}{$\mathrm{CPE}_{1}$} & \multirow{2}{*}{$\boldsymbol{R}_{c t}\left(\Omega \cdot \mathrm{cm}^{2}\right)$} & \multicolumn{2}{|c|}{$\mathrm{CPE}_{2}$} & \multirow{2}{*}{$W \times 10^{-4}\left(\Omega . \mathrm{cm}^{2}\right)$} & \multirow{2}{*}{$\chi^{2} \times 10^{-3}$} & \multirow{2}{*}{$\eta(\%)$} \\
\hline & & & $Y_{01} \times$ & $0^{-4}\left(\Omega^{-1} \mathrm{~cm}^{-2} \mathrm{~s}^{\mathrm{n}}\right) n_{1}$ & & $Y_{02} X$ & $0^{-4}\left(\Omega^{-1} \mathrm{~cm}^{-2} \mathrm{~s}^{\mathrm{n}}\right) n_{2}$ & & & \\
\hline Unpeened & 20.47 & 17.56 & 5.3 & 0.74 & 957 & 4.8 & 0.69 & 2.27 & 41.5 & - \\
\hline 50 & 29.32 & 204.78 & 2.6 & 0.88 & 17,020 & 1.4 & 0.85 & - & 20.0 & 94.38 \\
\hline 70 & 27.15 & 151.40 & 2.2 & 0.84 & 9387 & 3.1 & 0.80 & - & 24.0 & 89.81 \\
\hline
\end{tabular}

previous electrochemical analysis. Fig. 11a shows the image of the unpeened bare polished $\mathrm{Cu}$ before flow corrosion, whereas Fig. 11b-d show the images of the bare $\mathrm{Cu}$ at 120,240 , and $360 \mathrm{rpm}$ after corrosion showing a progressive trend in the surface damage from micro holes at $120 \mathrm{rpm}$ to crack initiation at $240 \mathrm{rpm}$ and deep cracks at $360 \mathrm{rpm}$. In the case of the peened $\mathrm{Cu}$ surface, observable pitting corrosion occurred only at the $360 \mathrm{rpm}$ (Fig. 11h), prior to that, the surface remained intact with minor tribological effects at 120 and $240 \mathrm{rpm}$ (Fig. 11f and $\mathrm{g}$ ).

\subsection{AFM analysis for peened and unpeened Cu after corrosion}

Fig. 12 shows the AFM topographic analysis of the peened and the unpeened after flow corrosion with their respective roughness profiles. The peened surface (Fig. 12a) showed a more even topology with reduced roughness $\left(R_{t}\right)$ and arithmetic deviation of the roughness profile $\left(R_{a}\right)$ in the range of 0.116 and $0.038 \mu \mathrm{m}$ respectively, (see Fig. 12b). Whereas in the case of the unpeened (Fig. 12c), the surface was uneven and heavily damaged after corrosion with higher $R_{t}$ and $R_{a}$ in the range of 0.969 and $0.121 \mu \mathrm{m}$ respectively, (see Fig. 12d). Overall, the research showed that the laser-peened $\mathrm{Cu}$ surface showed higher resistance to aggressive corrosive $3.5 \% \mathrm{NaCl}$ medium than the unpeened $\mathrm{Cu}$ surface with the LSPVC $50 \%$ proven as the best preforming peening parameter both under static and flow conditions.

\subsection{Comparison of the present method with existing literature}

At the end of the data acquisition and analysis, to understand the overall progress made, the results obtained in the present research work was compared to some of the prominent $\mathrm{Cu}$ corrosion protection methods in neutral chloride medium reported in the literature. Table 4 shows the corrosion current densities, protection efficiencies $(\eta)$, and corrosion rates obtained by using different materials and methods such as the direct dissolution of corrosion inhibitors in the corrosive electrolyte, pre-treatment before immersion, self-assembly monolayer 


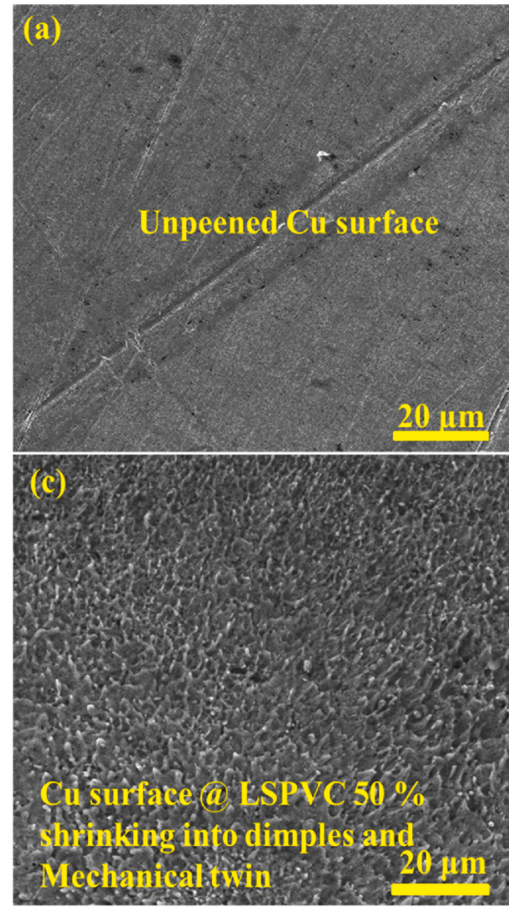

Before
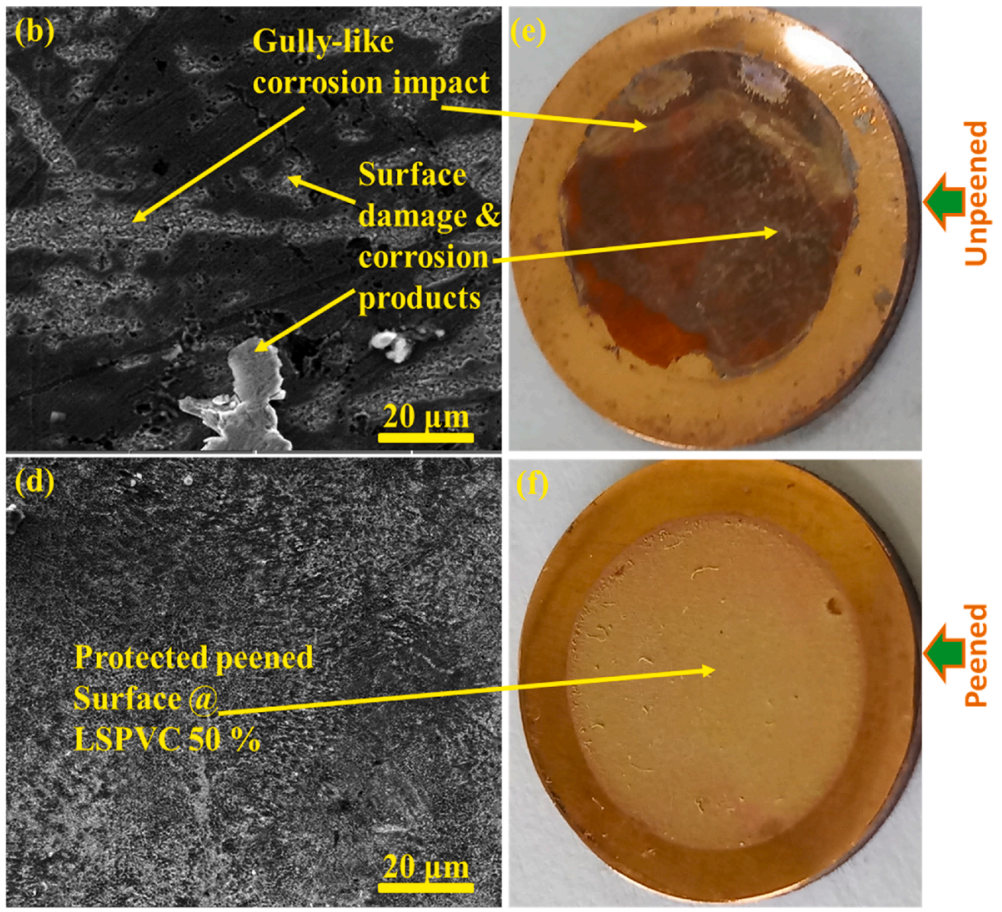

after corrosion, static long immersion condition

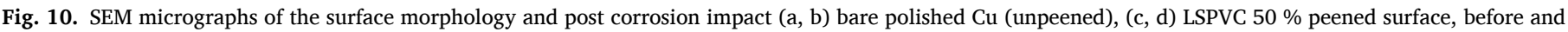

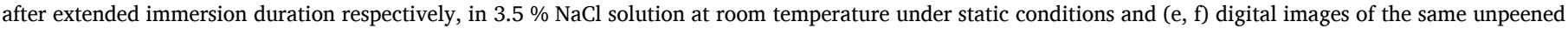
and peened surfaces respectively, taken at the end of the immersion experiment.
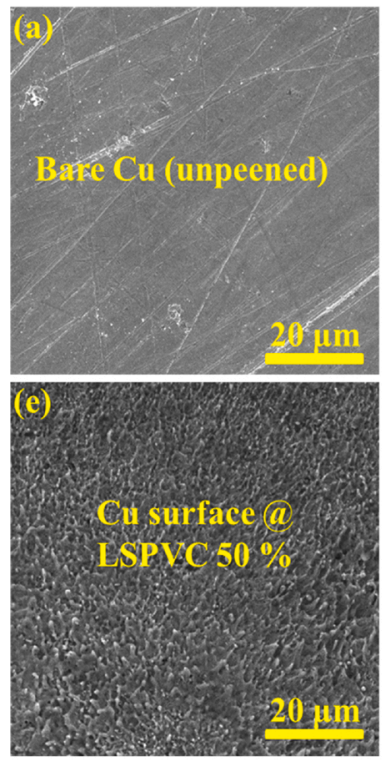

Before
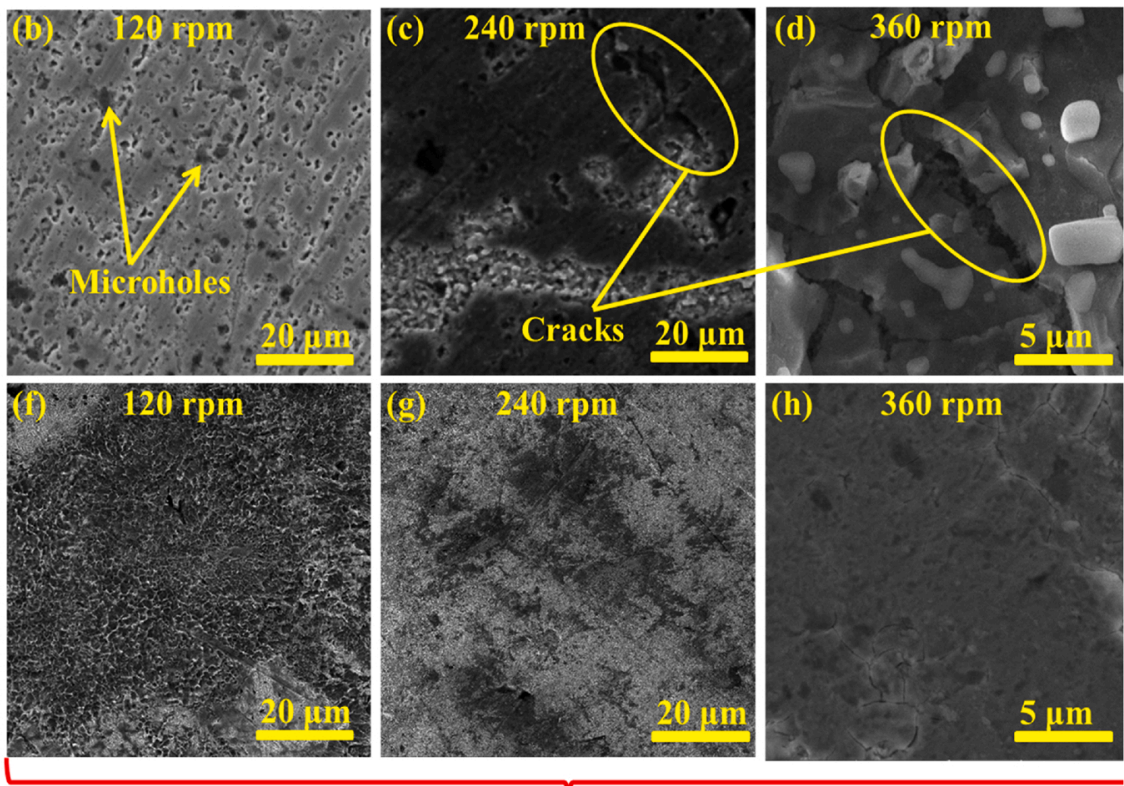

After flow corrosion at different rpm, 120, 240 and 360

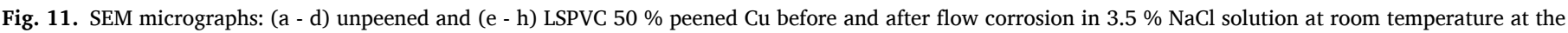
rotation speeds of 120,240 and $360 \mathrm{rpm}$.

(SAM), metal plating and different types of coatings for $\mathrm{Cu}$ protection. In Table 4 , the highest protection efficiency $(\eta)(98.7 \%)$ and lowest corrosion current density $\left(0.06 \mu \mathrm{A} \mathrm{cm}^{-2}\right)$ was reported for $\mathrm{Cu}$ in $3 \%$ $\mathrm{NaCl}$ medium for benzotriazole (BTA) inhibitor via pre-treatment method [57]. By dissolving in the artificial seawater the BTA yielded $95.0 \%$ efficiency [58]. Taking the concentration of the aggressive electrolyte into consideration, in $3.5 \% \mathrm{NaCl}$, the highest efficiency and lowest corrosion current density of $94.7 \%$ and $0.38 \mu \mathrm{A} \mathrm{cm}{ }^{-2}$ respectively, was reported for dipotassium 4,4'-\{benzene-1,4-diyl-bis-[(1E)-3-oxoprop-1-ene-1,3-diyl]\}-bis-[2-(2H-benzo-

triazol-2-yl)-phenol ate] (C1) dissolved in the electrolyte [60]. Several other methods achieved lower efficiencies compared to BTA and C1. However, with LSPVC process the performance in $3.5 \% \mathrm{NaCl}$ has improved to a value close to that of $\mathrm{C} 1$, which is encouraging since BTA 

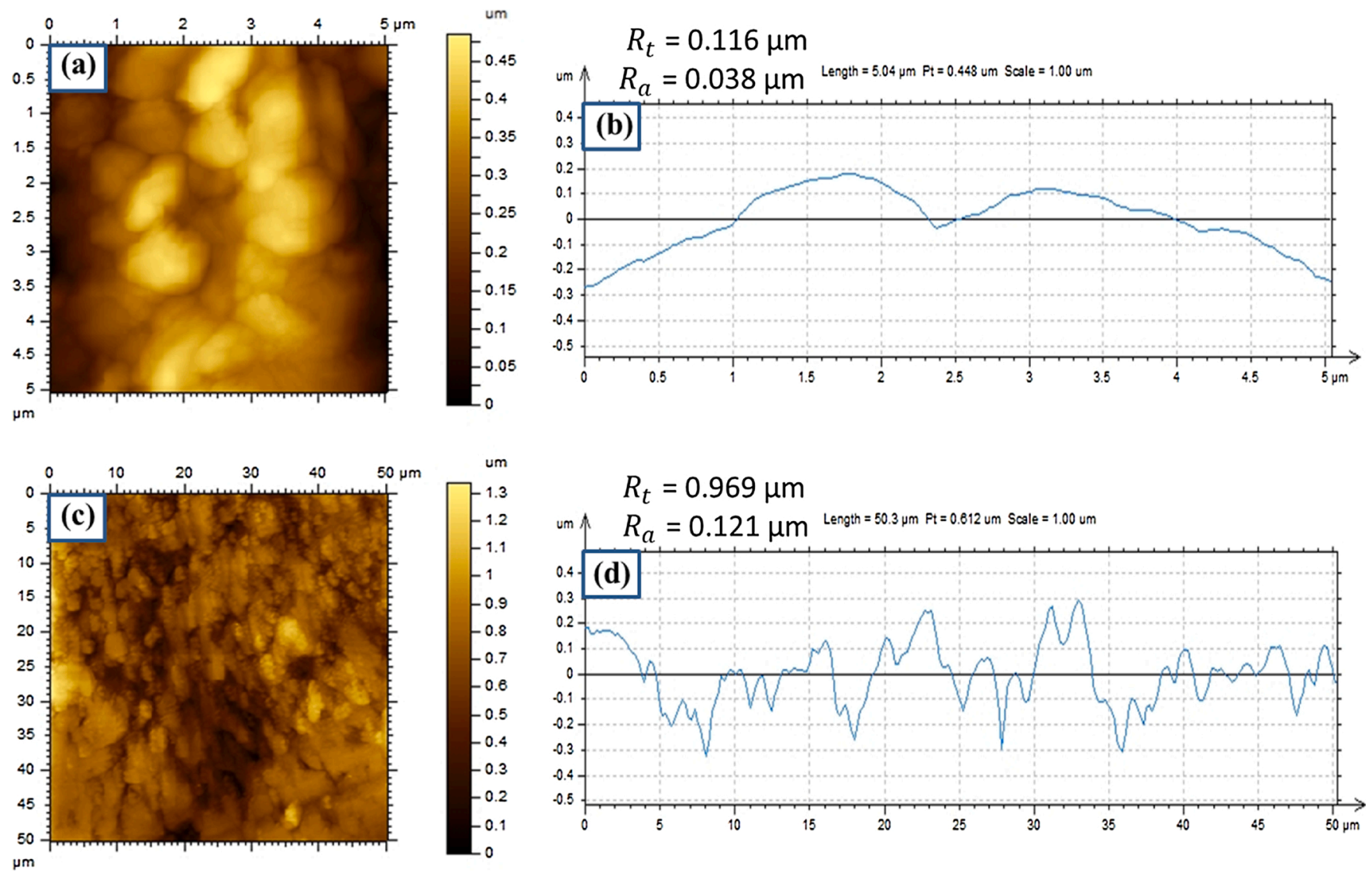

Fig. 12. AFM analysis of the surface topology (a, c) and roughness profile (b, d) of LSPVC $50 \%$ peened and unpeened bare Cu surface after extended immersion in $3.5 \% \mathrm{NaCl}$ solution.

Table 4

Comparison chart for the performance of the previous state of the art corrosion inhibitors based on polarization tests for copper in chloride medium with the present research.

\begin{tabular}{|c|c|c|c|c|c|c|c|}
\hline Inhibitor & Electrolyte & Method of testing & $\begin{array}{l}I_{\text {corr }}(\mu \mathrm{A} \\
\left.\mathrm{cm}^{-2}\right)\end{array}$ & $\begin{array}{l}\eta \\
(\%)\end{array}$ & $\begin{array}{l}C R \\
\text { (mmpy) }\end{array}$ & Authors & Ref. \\
\hline Benzotriazole (BTA) & $3 \% \mathrm{NaCl}$ & Pre-treated & 0.06 & 98.7 & - & Notoya et al. & [57] \\
\hline Benzotriazole (BTA & $\begin{array}{l}\text { Artificial sea } \\
\text { water }\end{array}$ & $\begin{array}{l}\text { Dissolved in } \\
\text { electrolyte }\end{array}$ & - & 95.0 & - & Bokati et al. & [58] \\
\hline 4-Methyl-5-vinylthiazole & $3 \% \mathrm{NaCl}$ & $\begin{array}{l}\text { Dissolved in } \\
\text { electrolyte }\end{array}$ & 0.42 & 94.5 & - & Mo et al. & [59] \\
\hline $\begin{array}{l}\text { Dipotassium 4,4'-\{benzene-1,4-diyl-bis-[(1E)-3-oxoprop-1-ene-1,3- } \\
\text { diyl]\}-bis-[2-(2H-benzotriazol-2-yl)-phenol ate] (C1) }\end{array}$ & $3.5 \% \mathrm{NaCl}$ & $\begin{array}{l}\text { Dissolved in } \\
\text { electrolyte }\end{array}$ & 0.38 & 94.7 & - & Jing et al. & [60] \\
\hline 2-mercapto-4-amino-5-nitroso-6-hydroxy pyrimidine (MAP) & $3.5 \% \mathrm{NaCl}$ & $\begin{array}{l}\text { Dissolved in } \\
\text { electrolyte }\end{array}$ & 1.25 & 88.9 & - & Khaled & [61] \\
\hline Gemini surfactant & $3.5 \% \mathrm{NaCl}$ & $\begin{array}{l}\text { Dissolved in } \\
\text { electrolyte }\end{array}$ & 0.25 & 94.5 & 0.071 & Cao et al. & [62] \\
\hline Olive leaf extract & $3 \% \mathrm{NaCl}$ & $\begin{array}{l}\text { Dissolved in } \\
\text { electrolyte }\end{array}$ & 0.60 & $\begin{array}{l}86 \\
.5\end{array}$ & 0.007 & Rahal et al. & [63] \\
\hline Superhydrophobicelectroactive epoxy & $3.5 \% \mathrm{NaCl}$ & $\begin{array}{l}\text { Conducting } \\
\text { polymer coated }\end{array}$ & 4.33 & 86.8 & - & He et al. & [64] \\
\hline Chitosan & $\begin{array}{l}\text { synthetic } \\
\text { seawater }\end{array}$ & $\begin{array}{l}\text { Biopolymer in } \\
\text { solution }\end{array}$ & 13.70 & 85.5 & - & El Mouaden et al. & [65] \\
\hline Nicotinamide & $3.5 \% \mathrm{NaCl}$ & $\begin{array}{l}\text { Drug mat. in } \\
\text { elctrolyte }\end{array}$ & 9.00 & 80.8 & - & Hippolyte et al. & [66] \\
\hline 2,4,6-Trimercapto-1,3,5-triazine & $0.3 \% \mathrm{NaCl}$ & SAM coated & 0.88 & 92.4 & - & Chen et al. & [67] \\
\hline 1-(3-Aminopropyl) imidazole & $3 \% \mathrm{NaCl}$ & SAM coated & 0.26 & 93.1 & - & $\begin{array}{l}\text { Durainatarajana } \\
\text { et al. }\end{array}$ & [68] \\
\hline Heptadecafluoro-1,1,2,2-tetradecyl & $3.5 \% \mathrm{NaCl}$ & Electro-plating & 0.40 & - & 0.005 & Fenghua Su & [69] \\
\hline Nickael film & $3.5 \% \mathrm{NaCl}$ & Metal coating & 3.00 & - & 0.035 & Zhen Yanga & [70] \\
\hline $\mathrm{CoWO}_{4}+\mathrm{TX}-100$ & $3.5 \% \mathrm{NaCl}$ & $\begin{array}{l}\text { Dissolved in } \\
\text { electrolyte }\end{array}$ & 0.78 & 90.0 & - & Chukwuike et al. & [30] \\
\hline Capped $\mathrm{NiWO}_{4}$ & $3.5 \% \mathrm{NaCl}$ & $\begin{array}{l}\text { Dissolved in } \\
\text { electrolyte }\end{array}$ & 0.35 & 94.3 & 0.008 & Chukwuike et al. & [29] \\
\hline Laser residual stress & $3.5 \% \mathrm{NaCl}$ & LSP & 0.35 & 94.5 & 0.008 & Present & - \\
\hline
\end{tabular}


was carried out in $3 \% \mathrm{NaCl}$. In this work, the corrosion current density of $\mathrm{Cu}$ was brought down progressively from $6.31 \mu \mathrm{A} \mathrm{cm}{ }^{-2}$ to $0.35 \mu \mathrm{A}$ $\mathrm{cm}^{-2}$ with a protection efficiency of $94.45 \%$ by using LSPVC peening process. These results are obtained under static conditions. In the present experiment; we went further to validate the achieved performance of static medium by subjecting the peened surface to a more aggressive flow environment and prolonged immersion tests. The overall results showed that the LSPVC process has the potential of effective corrosion protection of $\mathrm{Cu}$ in the chloride medium.

\section{Conclusions}

Laser shock peening was employed for $\mathrm{Cu}$ surface modification. The results showed improved corrosion resistance under static and flow corrosive medium of $3.5 \% \mathrm{NaCl}$ at the open atmosphere and room temperature. Thus, the research highlights the following key points:

There was a progressive change in the mechanical properties of $\mathrm{Cu}$ with laser light treatment at various overlaps (40,50, and $70 \%)$. This lead to increased hardness and a decrease in indentation depth penetration as a consequence of comprehensive residual stress from the laser light which improved the compact nature of the $\mathrm{Cu}$ surface.

Residual stress does not increase indefinitely with the increase in the laser overlap but there exists an optimal value above or below which the laser light might not impact directly on the residual stress. At a low value the impact energy might be too weak for effective modification while above certain value the energy becomes too high, thus converts to surface damage at the same time the sacrificial layer becomes consumed. In the present research, a $50 \%$ overlap showed the most effective residual stress accumulation without surface damage.

It is possible to conclude that with moderate overlap (50\%) at an appropriate power density $\left(8 \mathrm{Gw} / \mathrm{cm}^{2}\right)$ int presence of PVC minimal surface roughness can be achieved with LSPVC modification. This resulted in high resistance to corrosion to the tune of $17,020 \Omega . \mathrm{cm}^{2}$ in $3.5 \% \mathrm{NaCl}$ compared to $958 \Omega . \mathrm{cm}^{2}$ of the unpeened $\mathrm{Cu}$ surface. Reduction in the corrosion current density was found from 6.31 to 0.35 $\mu \mathrm{A} \mathrm{cm}{ }^{-2}$ equivalent to protection efficiency of $94.45 \%$.

The mechanism of this operation involves the inducement of residual stress to the $\mathrm{Cu}$ surface. Shrinking and intertwining of the top-surface structures leading to a more compact surface with minor roughness. This resulted in the increased top-surface hardness and hydrophobicity of $\mathrm{Cu}$ leading to a new surface with high corrosion resistance.

\section{Data availability}

The raw/processed data required to reproduce these findings cannot be shared at this time as the data also forms part of an on-going study.

\section{Author statement}

Author Agreement Statement, We the undersigned declare that this manuscript is original, has not been published before and is not currently being considered for publication elsewhere. We confirm that the manuscript has been read and approved by all named authors and that there are no other persons who satisfied the criteria for authorship but are not listed. We further confirm that the order of authors listed in the manuscript has been approved by all of us. We understand that the Corresponding Author is the sole contact for the Editorial process. He/ she is responsible for communicating with the other authors about progress, submissions of revisions and final approval of proofs Signed by all authors as follows:

V.I. Chukwuike, O.G. Echem, S. Prabhakaran, S. AnandKumar, R. C. Barik*

\section{Declaration of Competing Interest}

The authors declare that there is no conflict of interest regarding the publication of this paper.

\section{Acknowledgments}

Council of Scientific and Industrial Research (CSIR), India, and The World Academy of Sciences (TWAS), Italy are gratefully acknowledged by Chukwuike for the CSIR-TWAS Postgraduate Fellowship (Award No. 22/FF/CSIR-TWAS/2016) to pursue a Ph.D. research program in CSIRCECRI, India. This work was financially supported by the Science and Engineering Research Board, DST India under the Extramural Research (EMR) funding scheme (EMR/2016/003316). V.I.C is grateful to the Academy of Scientific and Innovative Research (AcSIR), CSIR-CECRI, India for PhD curriculum. All the authors wish to thank the Central Instrument Facility (CIF), CSIR-CECRI for extending the characterization facilities.

\section{Appendix A. Supplementary data}

Supplementary material related to this article can be found, in the online version, at doi:https://doi.org/10.1016/j.corsci.2020.109156.

\section{References}

[1] D.V. Tripkovic, D. Strmcnik, D. van der Vliet, V. Stamenkovic, N.M. Markovic, The role of anions in surface electrochemistry, Faraday Dis. 140 (2008) 9-10, https:// doi.org/10.1039/b814058h.

[2] C.D. Fernández-Solis, A. Vimalanandan, A. Altin, J.S. Mondragón-Ochoa, K. Kreth, P. Keil, A. Erbe, Fundamentals of electrochemistry corrosion and corrosion protection, Soft Matter at Aqueous Interfaces 917 (2016) 29-70, https://doi.org/ 10.1007/978-3-319-24502-7.

[3] S. Prabhakaran, A. Kulkarni, G. Vasanth, S. Kalainathan, P. Shukla, V. K. Vasudevan, Laser shock peening without coating induced residual stress distribution, wettability characteristics and enhanced pitting corrosion resistance of austenitic stainless steel, Appl. Surf. Sci. 428 (2018) 17-30, https://doi.org/ 10.1016/j.apsusc.2017.09.138.

[4] T. Venugopal, K. Prasad Rao, B.S. Murty, Mechanical and electrical properties of Cu-Ta nanocomposites prepared by high-energy ball milling, Acta Mater. 55 (2007) 4439-4445, https://doi.org/10.1016/j.actamat.2007.04.025.

[5] Y. Pang, P. Li, H.S. Kim, Y. Gong, Y. Shen, L. Sun, X. Zhu, Strain softening induced by high pressure torsion in copper alloys, Mat. Trans. 56 (2015) 1658-1663, https://doi.org/10.2320/matertrans.MA201579.

[6] S. Prabhakaran, S. Kalainathan, Warm laser shock peening without coating induced phase transformations and pinning effect on fatigue life of low-alloy steel, Mat. Des. 107 (2016) 98-107, https://doi.org/10.1016/j.matdes.2016.06.026.

[7] G. Ranjith Kumar, G. Rajyalakshmi, S. Swaroop, S. Arul Xavier Stango, U. Vijayalakshmi, Laser shock peening wavelength conditions for enhancing corrosion behaviour of titanium alloy in chloride environment, J. Braz. Soc. Mech. Sci. Engin. 41 (2019) 1-18, https://doi.org/10.1007/s40430-019-1633-y.

[8] M. Ebrahimi, S. Amini, S.M. Mahdavi, The investigation of laser shock peening effects on corrosion and hardness properties of ANSI 316L stainless steel, Inter. J. Adv. Manuf. Tech. 88 (2017) 1557-1565, https://doi.org/10.1007/s00170-0168873-0.

[9] H. Wang, Y. Huang, Z. Du, W. Zhang, M. Bi, Effect of laser shock peening on electrochemical corrosion resistance of 2024 aluminum alloy, in: ASME 2016 11th Inter. Manufacturing Sci. Eng. Conference, MSEC 2016, 2016, p. 1, https://doi.org/ 10.1115/MSEC20168549.

[10] L. Vilela Costa, J.R. Gonçalves Carneiro, R. Pinto Coelho Catalão, O.K. Ribas, P. Brito, Residual stress gradients in AISI 9254 steel springs submitted to shot peening and heat treatment for increased fatigue resistance, Adv. Mat. Res. 996 (2014) 749-754, https://doi.org/10.4028/www.scientific.net/AMR.996.749.

[11] I.F. Pariente, M. Guagliano, Influence of shot peening process on contact fatigue behavior of gears, Mat. Manuf. Process. 24 (2009) 1436-1441, https://doi.org/ 10.1080/10426910903386097.

[12] S. Prabhakaran, S. Kalainathan, Compound technology of manufacturing and multiple laser peening on microstructure and fatigue life of dual-phase spring steel, Mat. Sci. Eng. A 674 (2016) 634-645, https://doi.org/10.1016/j. msea.2016.08.031.

[13] A.S. Gill, A. Telang, V.K. Vasudevan, Characteristics of surface layers formed on inconel 718 by laser shock peening with and without a protective coating, J. Mat. Proces. Tech. 225 (2015) 463-472, https://doi.org/10.1016/j. jmatprotec.2015.06.026.

[14] Y. Sano, K. Akita, K. Masaki, Y. Ochi, I. Altenberger, B. Scholtes, Laser peening without coating as a surface enhancement technology, J. Laser Micro Nanoeng. 1 (2006) 161-166, https://doi.org/10.2961/jlmn.2006.03.0002.

[15] S. Niehoff, F. Vollertsen, Laser induced shock waves in deformation processing, Metalurgija 11 (2005) 183-194.

[16] X.D. Liu, D.G. Shang, M. Li, J. Jin, T. Chen, Y.B. Guo, M.E. Barkey, Healing fatigue damage by laser shock peening for copper film, Inter. J. Fatigue 54 (2013) 127-132, https://doi.org/10.1016/j.ijfatigue.2013.03.013. 
[17] Y. Geng, X. Mei, K. Wang, X. Dong, X. Yan, Z. Fan, W. Duan, W. Wang, Effect of laser shock peening on residual stress, microstructure and hot corrosion behavior of damage-tolerant TC21 titanium alloy, J. Mat. Eng. Perform. 27 (2018) 4703-4713, https://doi.org/10.1007/s11665-018-3575-4.

[18] Y. Guo, M.P. Sealy, C. Guo, Significant improvement of corrosion resistance of biodegradable metallic implants processed by laser shock peening, CIRP Ann. Manuf. Tech. 61 (2012) 583-586, https://doi.org/10.1016/j.cirp.2012.03.125.

[19] R. Zhang, S. Mankoci, N. Walters, H. Gao, H. Zhang, X. Hou, H. Qin, Z. Ren, X. Zhou, G.L. Doll, A. Martini, N. Sahai, Y. Dong, C. Ye, Effects of laser shock peening on the corrosion behavior and biocompatibility of a nickel-titanium alloy, J. Biomed. Mater. Res. Part B Appl. Biomater. 107 (2019) 1854-1863, https://doi org $/ 10.1002 / j b m . b .34278$.

[20] Y. Fan, E. Guo, Y. Dai, Response of copper's microstructure to laser shock peening, Emerg. Mat. Res. 7 (2018) 32-37, https://doi.org/10.1680/jemmr.16.00119.

[21] M. Froidevaux, P. Piatt, M. Cooper, K. Watkins, Laser interactions with copper, copper alloys and their corrosion products used in outdoor sculpture in the United Kingdom, Lasers in the Conservation of Artworks - Proceedings of the International Conference LACONA 7 (2008) 277-284, https://doi.org/10.1201/ 9780203882085.pt6.

[22] R. Oltra, G.M. Indrianjafy, M. Keddam, H. Takenouti, Laser depassivation of a channel flow double-electrode: a new technique in repassivation studies, Corros. Sci. 35 (1993) 827-832, https://doi.org/10.1016/0010-938X(93)90221-2.

[23] C. Park, D. Jung, E.J. Chun, S. Ahn, H. Jang, Y.J. Kim, Effect of laser shock peening without coating on fretting corrosion of copper contacts, Appl. Surf. Sci. 514 (2020) 1-57, https://doi.org/10.1016/j.apsusc.2020.145917.

[24] R.S. Prasannakumar, V.I. Chukwuike, K. Bhakyaraj, S. Mohan, R.C. Barik, Electrochemical and hydrodynamic flow characterization of corrosion protection persistence of nickel / multiwalled carbon nanotubes composite coating, Appl. Surf. Sci. (2019), 145073, https://doi.org/10.1016/j.apsusc.2019.145073.

[25] F. Arjmand, A. Adriaens, Influence of $\mathrm{pH}$ and chloride concentration on the corrosion behavior of unalloyed copper in $\mathrm{NaCl}$ solution: a comparative study between the micro and macro scales, Materials 5 (2012) 2439-2464, https://doi. org/10.3390/ma5122439.

[26] N.H. Helal, M.R. Negem, Electrochemical behaviour of some copper alloys in sodium chloride solutions containing different inorganic additives, Mat. Sci. 1 (2010) 8-22.

[27] J.A. Wharton, R.C. Barik, G. Kear, R.J.K. Wood, K.R. Stokes, F.C. Walsh, The corrosion of nickel-aluminium bronze in seawater, Corros. Sci. 47 (2005) 3336-3367, https://doi.org/10.1016/j.corsci.2005.05.053.

[28] A. Bhattacharya, S. Madan, C. Dashora, S. Prabhakaran, V.K. Manupati, S. Kalainathan, Effect of multiple laser shock peening on the mechanical properties of ETP, Mech., Mat. Sci. Eng. 06 (2017) 2412-5954, https://doi.org/10.2412/ mmse.77.9.503.

[29] V.I. Chukwuike, S.S. Sankar, S. Kundu, R.C. Barik, Capped and uncapped nickel tungstate $\left(\mathrm{NiWO}_{4}\right)$ nanomaterials : a comparison study for anti-corrosion of copper metal in NaCl solution, Corros. Sci. 158 (2019), 108101, https://doi.org/10.1016/ j.corsci.2019.108101.

[30] V.I. Chukwuike, S.S. Sankar, S. Kundu, R.C. Barik, Nanostructured cobalt tungstate $\left(\mathrm{CoWO}_{4}\right)$ : a highly promising material for fabrication of protective oxide film on copper in chloride medium, J. Electrochem. Soc. 166 (2019) 631-641, https://doi. org/10.1149/2.0771916jes.

[31] C. Mandolfino, M. Pizzorni, E. Lertora, C. Gambaro, Laser surface pre-treatment of polyolefin substrates for adhesive bonding, AIP Conference Proceedings 2113 (2019) 1-6, https://doi.org/10.1063/1.5112607.

[32] D. De Luca, I. Delfino, M. Lepore, Laser safety standards and measurements of hazard parameters for medical lasers, Inter. J. Optics Appl. 2 (2013) 80-86, https://doi.org/10.5923/j.optics.20120206.01.

[33] L. Vilela Costa, J.R. Gonçalves Carneiro, R. Pinto Coelho Catalão, O.K. Ribas, P. Brito, Residual stress gradients in AISI 9254 steel springs submitted to shot peening and heat treatment for increased fatigue resistance, Adv. Mat. Res. 996 (2014) 749-754, https://doi.org/10.4028/www.scientific.net/AMR.996.749.

[34] P. Yella, P. Venkateswarlu, R.K. Buddu, D.V. Vidyasagar, K.B. Sankara Rao, P. P. Kiran, K.V. Rajulapati, Laser shock peening studies on SS316LN plate with various sacrificial layers, Appl. Surf. Sci. 435 (2018) 271-280, https://doi.org/ 10.1016/j.apsusc.2017.11.088.

[35] Y. Jain, S. Varin, S. Prabhakaran, S. Kalainathan, Influence of multiple laser shock peening without coating on Ti-6Al-4V Alloy for aircraft applications, Mech. Mat. Sci. Eng. (2017) 363-367, https://doi.org/10.2412/mmse.65.57.424.

[36] A. Salimianrizi, E. Foroozmehr, M. Badrossamay, H. Farrokhpour, Effect of laser shock peening on surface properties and residual stress of Al6061-T6, Optics Lasers Eng. 77 (2016) 112-117, https://doi.org/10.1016/j.optlaseng.2015.08.001.

[37] J. Kusinski, S. Kac, A. Kopia, A. Radziszewska, M. Rozmus-Górnikowska, B. Major, L. Major, J. Marczak, A. Lisiecki, Laser modification of the materials surface layer-a review paper, Bull. Polish Acad. Sci. Tech. Sci. 60 (2012) 711-728, https://doi. org/10.2478/v10175-012-0083-9.

[38] C.L. Alexander, B. Tribollet, M.E. Orazem, Contribution of surface distributions to constant-phase-element (CPE) behavior : 1. influence of roughness, Electrochim. Acta 173 (2015) 416-424, https://doi.org/10.1016/j.electacta.2015.05.010.

[39] J.S. Ruzankina, O.S. Vasiliev, Study on possibility for the improvement of corrosion resistance of metals using laser-formed oxide surface structure, J. Phys. Conf. Ser. 735 (2016) 1-5, https://doi.org/10.1088/1742-6596/735/1/012050.

[40] U. Trdan, J.A. Porro, J.L. Ocaña, J. Grum, Laser shock peening without absorbent coating (LSPwC) effect on 3D surface topography and mechanical properties of 6082-T651 Al alloy, Surf. Coat. Tech. 208 (2012) 109-116, https://doi.org/ 10.1016/j.surfcoat.2012.08.048.
[41] S.A. Kumar, R. Sundar, S.G.S. Raman, R. Gnanamoorthy, R. Kaul, K. Ranganathan, K.S. Bindra, Effects of laser peening on fretting wear behaviour of alloy 718 fretted against two different counterbody materials, J. Eng. Tribol. 0 (2017) 1-13, https:// doi.org/10.1177/1350650117692707.

[42] F.O. Neves, A.C. Moreira, A.S. Chaves da Silva, Evaluation of residual stress on steel parts welded and milled, Adv. Mater. Sci. Eng. 2018 (2018) 1-5, https://doi. org/10.1155/2018/4826020.

[43] K. Kese, D.J. Rowcliffe, Nanoindentation method for measuring residual stress in brittle materials, J. Am. Ceram. Soc. 86 (2003) 811-816, https://doi.org/10.1111/ j.1151-2916.2003.tb03380.x.

[44] L.N. Zhu, B.S. Xu, H.D. Wang, C.B. Wang, Measurement of residual stresses using nanoindentation method, Crit. Rev. Solid State Mater. Sci. 40 (2015) 77-89, https://doi.org/10.1080/10408436.2014.940442.

[45] D. Wang, B. Xiang, Y. Liang, S. Song, C. Liu, Corrosion control of copper in 3.5 wt. $\% \mathrm{NaCl}$ solution by domperidone: experimental and theoretical study, Corros. Sci. 85 (2014) 77-86, https://doi.org/10.1016/j.corsci.2014.04.002.

[46] K.F. Khaled, M.N.H. Hamed, K.M. Abdel-Azim, N.S. Abdelshafi, Inhibition of copper corrosion in $3.5 \% \mathrm{NaCl}$ solutions by a new pyrimidine derivative: Electrochemical and computer simulation techniques, J. Solid State Electrochem. 15 (2011) 663-673, https://doi.org/10.1007/s10008-010-1110-0.

[47] H. Tian, Y.F. Cheng, W. Li, B. Hou, Triazolyl-acylhydrazone derivatives as novel inhibitors for copper corrosion in chloride solutions, Corros. Sci. 100 (2015) 341-352, https://doi.org/10.1016/j.corsci.2015.08.022.

[48] M. Galai, H. Benqlilou, M.E. Touhami, T. Belhaj, K. Berrami, H. El Kafssaoui, Comparative analysis for the corrosion susceptibility of copper alloys in sandy soil, Environ. Eng. Res. 23 (2018) 164-174, https://doi.org/10.4491/eer.2017.077.

[49] J. Balaji, M.G. Sethuraman, Improved corrosion resistance by forming multilayers over a copper surface by electrodeposition followed by a novel sol-gel coating method, RSC Adv. 6 (2016) 95396-95404, https://doi.org/10.1039/c6ra19173h.

[50] R.A. Buchanan, E.E. Stansbury, Handbook of Environmental Degradation of Materials: Electrochem. Corrosion, second edition, 2012, pp. 87-125, https://doi. org/10.1016/B978-1-4377-3455-3.00004-3. Delmar, NY, USA.

[51] D. Karthik, S. Arul Xavier Stango, U. Vijayalakshmi, S. Swaroop, Electrochemical behavior of laser shock peened Inconel 625 superalloy, Surf. Coat. Tech. 311 (2017) 46-54, https://doi.org/10.1016/j.surfcoat.2016.12.105.

[52] Z. Esen, E.B. Öcal, A. Akkaya, B. Gürçay, C. Özcan, B.A. Özgümüş, Ö. Duygulu, A. F. Dericioglu, Corrosion behaviours of Ti6Al4V-Mg/Mg-Alloy composites, Corros. Sci. 166 (2020), https://doi.org/10.1016/j.corsci.2020.108470. CS 108470.

[53] B.S. Hou, Q.H. Zhang, Y.Y. Li, G.Y. Zhu, G.A. Zhang, Influence of corrosion products on the inhibition effect of pyrimidine derivative for the corrosion of carbon steel under supercritical $\mathrm{CO}_{2}$ conditions, Corros. Sci. 166 (2020), https:// doi.org/10.1016/j.corsci.2020.108442. CS 108442.

[54] W. Nguyen, J.F. Duncan, T.M. Devine, C.P. Ostertag, Electrochemical polarization and impedance of reinforced concrete and hybrid fiber-reinforced concrete under cracked matrix conditions, Electrochim. Acta 271 (2018) 319-336, https://doi. org/10.1016/j.electacta.2018.03.134.

[55] K. Jüttner, W.J. Lorenz, W. Paatsch, The role of surface inhomogeneities in corrosion processes-electrochemical impedance spectroscopy (EIS) on different aluminium oxide films, Corros. Sci. 29 (1989) 279-288, https://doi.org/10.1016/ 0010-938X(89)90036-X.

[56] C. Deslouis, B. Tribollet, G. Mengoli, M.M. Musiani, Electrochemical behaviour of copper in neutral aerated chloride solution. I. steady-state investigation, J. Appl. Electrochem. 18 (1988) 374-383.

[57] T. Notoya, G.W. Poling, Protection of copper by pretreatment with benzotriazole, Corrosion 35 (1979) 193-200, https://doi.org/10.5006/0010-9312-35.5.193.

[58] K. Sabet Bokati, C. Dehghanian, S. Yari, Corrosion inhibition of copper, mild steel and galvanically coupled copper-mild steel in artificial seawater in presence of $1 \mathrm{H}$ benzotriazole, sodium molybdate and sodium phosphate, Corros. Sci. 126 (2017) 272-285, https://doi.org/10.1016/j.corsci.2017.07.009.

[59] S. Mo, H.Q. Luo, N.B. Li, Study on the influences of two thiazole flavor ingredients on $\mathrm{Cu}$ corrosion caused by chloride ion, J. Colloid Interface Sci. 505 (2017) 929-939, https://doi.org/10.1016/j.jcis.2017.06.075.

[60] C. Jing, Z. Wang, Y. Gong, H. Huang, Y. Ma, H. Xie, H. Li, S. Zhang, F. Gao, Photo and thermally stable branched corrosion inhibitors containing two benzotriazole groups for copper in $3.5 \mathrm{wt} \%$ sodium chloride solution, Corros. Sci. 138 (2018) 353-371, https://doi.org/10.1016/j.corsci.2018.04.027.

[61] K.F. Khaled, Studies of the corrosion inhibition of copper in sodium chloride solutions using chemical and electrochemical measurements, Mat. Chem. Phys. 125 (2011) 427-433, https://doi.org/10.1016/j.matchemphys.2010.10.037.

[62] K. Cao, H.Y. Sun, B.R. Hou, Corrosion inhibition of gemini surfactant for copper in $3.5 \%$ NaCl, Adv. Mat. Res. 936 (2014) 1125-1131, https://doi.org/10.4028/ www.scientific.net/AMR.936.1125.

[63] C. Rahal, M. Masmoudi, R. Abdelhedi, R. Sabot, M. Jeannin, M. Bouaziz, P. Refait, Olive leaf extract as natural corrosion inhibitor for pure copper in $0.5 \mathrm{M} \mathrm{NaCl}$ solution: a study by voltammetry around OCP, J. Electroanal. Chem. 769 (2016) 53-61, https://doi.org/10.1016/j.jelechem.2016.03.010.

[64] G. He, S. Lu, W. Xu, S. Szunerits, R. Boukherroub, H. Zhang, Controllable growth of durable superhydrophobic coatings on a copper substrate via electrodeposition, Phys. Chem. Chem. Phys. 17 (2015) 10871-10880, https://doi.org/10.1039/ c5cp00059a.

[65] K. El Mouaden, B. El Ibrahimi, R. Oukhrib, L. Bazzi, B. Hammouti, O. Jbara, A. Tara, D.S. Chauhan, M.A. Quraishi, Chitosan polymer as a green corrosion inhibitor for copper in sulfide-containing synthetic seawater, Inter. J. Biol. Macro. 119 (2018) 1311-1323, https://doi.org/10.1016/j.ijbiomac.2018.07.182.

[66] C.N. Hippolyte, B.Y. Serge, A. Sagne, J. Creus, T. Albert, Nicotinamide inhibition properties for copper corrosion in $3.5 \% \mathrm{NaCl}$ solution: experimental and 
theoretical investigations, J. Mat. Sci. Chem. Eng. 06 (2018) 100-121, https://doi. org $/ 10.4236 /$ msce.2018.63008.

[67] W. Chen, S. Hong, H.Q. Luo, N.B. Li, Inhibition effect of 2,4,6-trimercapto-1,3,5triazine self-assembled monolayers on copper corrosion in $\mathrm{NaCl}$ solution, J. Mat. Eng. Perform. 23 (2014) 527-537, https://doi.org/10.1007/s11665-013-0788-4.

[68] P. Durainatarajan, M. Prabakaran, S. Ramesh, V. Periasamy, Self-assembly on copper surface by using imidazole derivative for corrosion protection, J. Adhesion Sci. Tech. 32 (2018) 1733-1749, https://doi.org/10.1080/

01694243.2018 .1444004$.
[69] F. Su, K. Yao, Facile fabrication of superhydrophobic surface with excellent mechanical abrasion and corrosion resistance on copper substrate by a novel method, ACS Appl. Mat. Interfaces 6 (2014) 8762-8770, https://doi.org/10.1021/ am501539b.

[70] Z. Yang, X. Liu, Y. Tian, Fabrication of super-hydrophobic nickel film on copper substrate with improved corrosion inhibition by electrodeposition process, Colloids Surf. A 560 (2019) 205-212, https://doi.org/10.1016/j.colsurfa.2018.10.024. 